\title{
Application of response surface methodology for optimization of biosorption of fluoride from groundwater using Shorea robusta flower petal
}

\author{
G. Biswas ${ }^{1}$ M. Kumari' ${ }^{2}$ K. Adhikari ${ }^{2} \cdot$ S. Dutta ${ }^{1}$
}

Received: 8 February 2017/Accepted: 5 October 2017/Published online: 14 October 2017

(c) The Author(s) 2017. This article is an open access publication

\begin{abstract}
Fluoride pollution in groundwater is a major concern in rural areas. The flower petal of Shorea robusta, commonly known as sal tree, is used in the present study both in its native form and Ca-impregnated activated form to eradicate excess fluoride from simulated wastewater. Response surface methodology (RSM) was used for experimental designing and analyzing optimum condition for carbonization vis-à-vis calcium impregnation for preparation of adsorbent. During carbonization, temperature, time and weight ratio of calcium chloride to sal flower petal (SFP) have been considered as input factors and percentage removal of fluoride as response. Optimum condition for carbonization has been obtained as temperature, $500{ }^{\circ} \mathrm{C}$; time, $1 \mathrm{~h}$ and weight ratio, 2.5 and the sample prepared has been termed as calcium-impregnated carbonized sal flower petal (CCSFP). Optimum condition as analyzed by one-factor-at-a-time (OFAT) method is initial fluoride concentration, $2.91 \mathrm{mg} / \mathrm{L} ; \mathrm{pH} 3$ and adsorbent dose, $4 \mathrm{~g} / \mathrm{L}$. CCSFP shows maximum removal of $98.5 \%$ at this condition. RSM has also been used for finding out optimum condition for defluoridation considering initial concentration, $\mathrm{pH}$ and adsorbent dose as input parameters.
\end{abstract}

Electronic supplementary material The online version of this article (doi:10.1007/s13201-017-0630-5) contains supplementary material, which is available to authorized users.

\section{S. Dutta}

susmita_che@yahoo.com

1 Department of Chemical Engineering, National Institute of Technology Durgapur, Durgapur 713209, India

2 Department of Earth and Environmental Studies, National Institute of Technology Durgapur, Durgapur 713209, India
The optimum condition as analyzed by RSM is: initial concentration, $5 \mathrm{mg} / \mathrm{L} ; \mathrm{pH} 3.5$ and adsorbent dose, $2 \mathrm{~g} / \mathrm{L}$. Kinetic and equilibrium data follow Ho pseudo-secondorder kinetic model and Freundlich isotherm model, respectively. Adsorption capacity of CCSFP has been found to be $5.465 \mathrm{mg} / \mathrm{g}$. At optimized condition, CCSFP has been found to remove fluoride (80.4\%) efficiently from groundwater collected from Bankura district in West Bengal, a fluoride-contaminated province in India.

Keywords Fluoride - Shorea robusta flower petal · Response surface methodology · Adsorption - Isotherm · Thermodynamics

\section{List of symbols}

$c_{\mathrm{e}} \quad$ Concentration of fluoride at equilibrium $(\mathrm{mg} / \mathrm{L})$

$\Delta G \quad$ Gibbs free energy $(\mathrm{kJ} / \mathrm{mol})$

$\Delta H \quad$ Change of enthalpy $(\mathrm{kJ} / \mathrm{mol})$

$k_{1} \quad$ Adsorption rate constant of Lagergren first-order adsorption rate equation $\left(\mathrm{min}^{-1}\right)$

$k_{2} \quad$ Adsorption rate constant of pseudo-second-order adsorption rate equation $\left(\mathrm{g} \mathrm{mg}^{-1} \mathrm{~min}^{-1}\right)$

$k_{\mathrm{p}} \quad$ Intra-particle diffusion coefficient $\left(\mathrm{g} \mathrm{mg}^{-1} \mathrm{~min}^{-1}\right)$

$K_{F} \quad$ Freundlich isotherm constant $\left[(\mathrm{mg} / \mathrm{g})(\mathrm{L} / \mathrm{mg})^{1 / n}\right]$

$K_{\mathrm{L}} \quad$ Langmuir isotherm constant $(\mathrm{L} / \mathrm{g})$

$K \quad$ Linear isotherm constant

$q_{\mathrm{m}} \quad$ Maximum adsorption capacity of the adsorbent $(\mathrm{mg} /$ g)

$q_{\mathrm{e}} \quad$ Solid phase concentration of fluoride at equilibrium $(\mathrm{mg} / \mathrm{g})$

$q_{t} \quad$ Solid phase concentration of fluoride at any time $t(\mathrm{mg} / \mathrm{g})$

$\Delta S \quad$ Change in entropy $(\mathrm{kJ} / \mathrm{mol} \mathrm{K})$

$t \quad$ Contact time (h) 


\section{Introduction}

Fluoride has dual effect on living system. While fluoride concentration greater than $1.5 \mathrm{mg} / \mathrm{L}$ leads to skeletal and dental fluorosis, concentration lower than $0.5 \mathrm{mg} / \mathrm{L}$ is responsible for tooth-decay since low level of fluoride helps to strengthen the enamel (Razbe et al. 2013). The permissible limit of fluoride in drinking water is $1.5 \mathrm{mg} / \mathrm{L}$ as set by World Health Organization (WHO 2006) and according to the report; about 260 million people consume fluoride-contaminated drinking water (2 L/adult/day) (Brindha and Elango 2011). Fluoride is usually present in the rock minerals as fluorspar, fluorapatite, mica, etc., (Mondal et al. 2013). In groundwater, high fluoride concentration generally occurs due to physical and geological structure of aquifers (Ganvir and Das 2011). The geochemistry of high fluoride in groundwater depends on low calcium concentration and alkaline condition ( $\mathrm{pH}$ 7.6-8.6), which are favorable for dissolution of fluorite mineral from the host rocks (Weinstein and Davison 2004). In urban and rural areas of India, groundwater is a major source of drinking water. In West Bengal, a part of Bankura, Birbhum and Burdwan districts, are highly affected by fluoride contamination in groundwater (Bhaumik and Mondal, 2016). At present, the techniques used for removal of fluoride may be broadly divided into four categories, i.e., membrane-separation (Meenakshi and Maheshwari 2006), ion-exchange (Mohapatra et al. 2009), precipitation-coagulation (Habuda-Stanić et al. 2014) and adsorption (Chakrabarty and Sarma 2012; Karthikeyan and Llango 2007; Zhang et al. 2011). Membrane-based technologies are based on the use of membranes for separation of fluoride from its contaminated water. Electro-dialysis drives away the solutes by using anion-exchange membranes under the driving force of an electric field (Meenakshi and Maheshwari 2006). Ion-exchange can remove fluoride up to $95 \%$ but this technique is very costly due to high cost of resin and post-treatment at low pH (Mohapatra et al. 2009). Nalgonda technique of fluoride removal is based on precipitation-coagulation. The following technique can remove only $18-33 \%$ fluoride and the greater part of the fluoride is converted to aluminium fluoride complexes, which is a toxic compound (Habuda-Stanić et al. 2014). In contrast to these, adsorption process is economically effective and ultimate fate of many contaminants in aquatic environment (Bhatnagar et al. 2011). Adsorption is basically a mass transfer-driven process and the adsorbate is adsorbed on the surface of adsorbent due to affinity of the adsorbent surface for a particular substance. A number of adsorbents can be used to defluoridate water (Karthikeyan and Llango 2007; Zhang et al. 2011); however, due to good reactivity of calcium $\left(\mathrm{Ca}^{2+}\right)$ and fluoride $\left(\mathrm{F}^{-}\right)$, researches are now trending towards the impregnation of calcium on the adsorbent for enhancement of removal of fluoride from its contaminated water (Bhaumik et al. 2012; HernándezMontoya et al. 2012; Zhang et al. 2011).

Shorea robusta, commonly known as sal tree, is a subdeciduous tree and high up to $30 \mathrm{~m}$. Sal tree has large leathery leaves and yellowish flowers. Sal trees are mainly found in Nepal and eastern part of India. The flowers bloom in the end of summers. The sal flower is whitish in color, and borne in raceme-like panicles in leaf axils. Except for indoor decoration with dry sal flower, it does not have any other usage. These flowers can be considered as bio-waste as they create trouble to the local people by blocking the open drainage system and damaging the aesthetic condition of the locality. Therefore, in the present study, initially raw sal flower petal (SFP) has been chosen to remove fluoride from simulated solution. Due to low capacity in removal of fluoride, it was impregnated with calcium at high temperature to enhance its adsorptive capability. As far the knowledge of present research group concerned, no study on adsorptive removal of pollutant using sal flower petal has been reported.

The conventional technique to optimize multivariable systems requires a lot of experiments to determine the optimum level which is a time-consuming process (Chatterjee et al. 2012). Such problems can be diminished by changing a number of variables at a time. This is possible by designing experiments statistically using statistical techniques such as response surface methodology (RSM) (Bhaumik et al. 2013). Besides getting optimum conditions, RSM has the advantage of studying the interaction between various input parameters at a time compared to one-factor-at-a-time (OFAT) analysis (Alkhatib et al. 2015). Such method involves (1) designing experiments in which the process parameters are varied statistically according to a set of experimental trials and determination of the output parameters; (2) analyzing the data and predicting empirical model using analysis of variance (ANOVA) and (3) numerical optimization (Yadav et al. 2013). Basic assumptions for ANOVA are normal distribution of responses, homogeneity of variance and individual samples (Sadhu et al. 2013). Hence, the statistical techniques have the advantages to develop, improve and optimize the relationship between a number of input variables and measured responses in short period of time (Sadhu et al. 2013). The main objective of RSM is to establish an empirical model statistically to obtain a valid result at a minimum resource, effort and time (Sadhu et al. 2013). In a number of research works on fluoride removal, RSM has been employed for optimization of electrocoagulation process (Behbahani et al. 2011), membrane techniques (Richards et al. 2009), adsorption process (Alugumuthu and Rajan 2010a, b; Rehman et al. 2015), etc. A number of plant derived biomaterials were used as 
precursor for preparation of adsorbents to be used for fluoride removal. RSM was used for optimization of preparation of adsorbents from such biomaterials, viz. tamarind seed, neem and kikar leaves (Kumar et al. 2008), neem charcoal (Chakrabarty and Sarma 2012), raw and treated lemon leaf (Bhaumik et al. 2013), thermally and chemically activated coconut fiber (Bhaumik and Mondal 2015), aluminium-impregnated coconut fiber (Mondal et al. 2015), banana peel dust (Bhaumik and Mondal 2016), aluminium-impregnated potato plant ash (Ghosh et al. 2016), etc. However, application of RSM both for preparation of adsorbent and removal of fluoride using prepared adsorbent is quite terse.

Therefore, in the present work, a comprehensive study starting from impregnation of calcium to raw sal flower petal, characterization, optimization of removal, kinetic and equilibrium studies with simulated solution has thus been carried out. Finally, defluoridation has been done using prepared adsorbent (CCSFP) from fluoride-contaminated groundwater, collected from fluoride-contaminated region in India and results are reported.

\section{Materials and methods}

\section{Preparation of SFP and CCSFP}

\section{Experimentation}

The dried sal flowers were collected from the campus of National Institute of Technology Durgapur, West Bengal, India. Calcium chloride (Merck, India) was used as an activating as well as impregnating agent. Petals were removed from the flowers manually, dried in sun for a week and later ground in a grinder. It was then sieved to get uniform size of $90 \mu$. The specific size $(90 \mu)$ was chosen based on the experiments performed with different size of particles ranging from 45 to $180 \mu$. Though highest removal (99\%) was obtained at $45 \mu$, the cost of grinding is more to get such low particle size. Since comparable removal was obtained with $90 \mu$ sized particle (98.4\%), all the experiments on fluoride removal were performed with such particle size. Kushwaha and Dutta (2017) performed their study with $90 \mu$ sized particle to remove copper $(\mathrm{Cu})$ from simulated wastewater. Ground sal flower petal was mixed thoroughly with definite amount of calcium chloride. The mixture was divided into several silica crucibles, suitable for high-temperature heating, and placed in an electrically operated and automatically controlled muffle furnace (Servotronics, DIC 9681, India). Response surface methodology was applied to optimize carbonization vis-à-vis calcium impregnation condition. Design Expert Software (Stat-Ease, Version:
8.0.6) was used for such purpose. Three parameters such as temperature of impregnation, time of impregnation and weight ratio of calcium chloride and SFP were considered as input parameters and percentage removal of fluoride as response. The minimum $(-1)$ and maximum $(+1)$ levels of these three numeric factors were kept as 450 and $550{ }^{\circ} \mathrm{C}$ for temperature, 1 and $2 \mathrm{~h}$ for time and 2.5 and 7.5 for weight ratio of calcium chloride and SFP. The statistical experimental design as done by Design Expert Software is shown in Table 1. After impregnation, sample was washed thoroughly with distilled water, until the $\mathrm{pH}$ of the draining water was neutral. The sample was then dried in an air oven at $60{ }^{\circ} \mathrm{C}$ overnight. It was then sieved to get $90 \mu$ sized particle and stored in an air-tight container for further use. Synthetic fluoride solution was prepared following standard protocol (Eugene et al. 2012). The Ca-impregnated carbonized samples, prepared at each operating condition, were brought into contact with the synthetic fluoride solution in a batch contactor at $\mathrm{pH} 3$ and $25^{\circ} \mathrm{C}$. The initial concentration of fluoride (10 mg/L), volume of solution $(50 \mathrm{~mL})$ and weight of Caimpregnated adsorbent sample $(0.3 \mathrm{~g})$ were kept constant at each experimental run. The residual concentration of fluoride was measured using ion-selective electrode (Ionmeter 4 Star, B 36531, Thermo-scientific) and finally, the percentage removal was calculated.

\section{Design of experiment}

The most popular class of second-order design is the central composite design (CCD) which permits to test lack of fit with less number of experiments (Myers et al. 2005). This design can easily be constructed by augmenting the fractional factorial design that was used for estimating the first-order model (Khuri 1996; Myers et al. 2005). The advantages of CCD lie in its use in sequential experimentation (Myers et al. 2005; Kumar et al. 2006; Garg et al. 2008; Bhatti et al. 2011; Alkhatib et al. 2015; Rehman et al. 2015). In the present study, the experimental design for calcium impregnation was done using the response surface methodology (RSM). Quantitative data obtained from the adequate experiments was analyzed by RSM to optimize the operating conditions estimating regression model equation (Bhaumik et al. 2013; Fakhri 2015; Fakhri and Behrouz 2015a; Ghosh et al. 2016; Mouelhi et al. 2015; Gupta et al. 2017).

Total number of experiments can be determined from the following equation:

$N=2^{n}+2 n+n_{c}$,

where $N$ is the total number of experiments required, $n$ is the number of factors and $n_{\mathrm{c}}$ is the center point. Since three parameters, viz. temperature, time and weight ratio of 
Table 1 Experimental design and response to prepare calcium-impregnated carbonized sal flower petal (CCSFP)

\begin{tabular}{|c|c|c|c|c|}
\hline Run & Time $(\mathrm{h})$ & Temperature $\left({ }^{\circ} \mathrm{C}\right)$ & Calcium chloride: $S F P$ & Fluoride removal (\%) \\
\hline 1 & 1.50 & 500 & 5 & 94.81 \\
\hline 2 & 1.50 & 584 & 5 & 97.91 \\
\hline 3 & 1.50 & 500 & 5 & 94.80 \\
\hline 4 & 1 & 450 & 2.5 & 84.80 \\
\hline 5 & 2 & 550 & 2.5 & 96.73 \\
\hline 6 & 2.34 & 500 & 5 & 89.41 \\
\hline 7 & 1.5 & 500 & 5 & 94.80 \\
\hline 8 & 1.5 & 500 & 9.2 & 24.8 \\
\hline 9 & 1.5 & 500 & 0.8 & 57.94 \\
\hline 10 & 2 & 450 & 7.5 & 23.33 \\
\hline 11 & 1 & 550 & 2.5 & 85.80 \\
\hline 12 & 1.5 & 500 & 5 & 94.80 \\
\hline 13 & 2 & 550 & 7.5 & 89.87 \\
\hline 14 & 2 & 450 & 2.5 & 70.70 \\
\hline 15 & 1.5 & 415.91 & 5 & 24.79 \\
\hline 16 & 1.5 & 500 & 5 & 94.80 \\
\hline 17 & 1 & 450 & 7.5 & 32.91 \\
\hline 18 & 0.66 & 500 & 5 & 96.46 \\
\hline 19 & 1.5 & 500 & 5 & 94.80 \\
\hline 20 & 1 & 550 & 7.5 & 97.19 \\
\hline
\end{tabular}

calcium chloride and SFP were considered as input variables, a total of 20 experimental conditions were designed (Table 1), and hence 20 adsorbents were prepared from each experimental condition.

The process may be modeled using the following polynomial equation:

$y=a_{0}+\sum_{i=1}^{n} a_{i} x_{i}+\left(\sum_{i=1}^{n} a_{i i} x_{i}\right)^{2}+\sum_{i=1}^{n-1} \sum_{j=i+1}^{n} a_{i j} x_{i} x_{j}$,

where $a_{\mathrm{o}}$ was the constant coefficient, $a_{i}$ was the linear coefficient, $a_{i i}$ was the quadratic coefficients, $a_{i j}$ was the interaction coefficients (Ozer et al. 2009; Alkhatib et al. $2015)$. The validity of the proposed polynomial equation was assessed by the values of $R^{2}, R_{\text {Adj }}^{2}$ and $R_{\text {Pred }}^{2}$. More was the value of $R^{2}$, more was the fitting of experimental data to the proposed polynomial equation (Bhaumik et al. 2013). Numerical optimization technique was adopted to determine optimum condition of calcium impregnation (Hernández-Montoya et al. 2012). The sample prepared at optimum condition was termed as calcium-impregnated carbonized sal flower petal (CCSFP).

\section{Characterization of SFP and CCSFP}

Physico-chemical characterization of sal flower petal (SFP) and Ca-impregnated carbonized sal flower petal (CCSFP) was done in terms of its bulk density, solid density, moisture content, ash content, volatile matter, fixed carbon content (CEFIC 1986). Specific sized $(90 \mu)$ particle was used in each case. $\mathrm{pH}_{\mathrm{zpc}}$ of SFP and CCSFP was determined by saltaddition method (Tentli-Sequeira et al. 2014). SEM (scanning electron microscope, HITACHI-S-3000 N, Japan), EDX (energy dispersive X-ray, HITACHI-S-3000 N, Japan) and FTIR (Fourier transform infrared spectrometer, Spectrum 100, Perkin Elmer) studies of CCSFP were carried out before and after fluoride adsorption. SEM studies were carried out to show the topographical characteristics of native and fluoride-loaded CCSFP. EDX analysis was done to obtain elements present on the adsorbent surface. FTIR spectroscopy study was done with the transparent pellet prepared by mixing finely ground CCSFP (raw and fluoride loaded) with $\mathrm{KBr}$ (Merck, India). BET (Brunner-EmmetTeller) surface area and pore volume of CCSFP were measured by nitrogen adsorption-desorption isotherm method using Quantachrome ${ }^{\circledR}$ ASiQwin ${ }^{\mathrm{TM}}$-Automated Gas Sorption (Germany). 


\section{Fluoride removal study using CCSFP}

\section{Kinetic study}

Simulated fluoride solution $(1000 \mathrm{mg} / \mathrm{L})$ was prepared by dissolving $2.211 \mathrm{~g}$ of $\mathrm{NaF}$ (Merck, India) in $1.0 \mathrm{~L}$ deionized water (Eugene et al. 2012). Fluoride solutions of desired initial concentration were prepared by diluting stock solution using requisite amount of water. Several parameters such as initial concentration of fluoride, adsorbent dose, $\mathrm{pH}$, particle size and temperature generally affect the kinetics of adsorption process (Alkhatib et al. 2015; Chakrapani et al. 2010; Rehman et al. 2015) and the success of adsorption process depends on the proper selection of key parameters and their ranges. In the present case, since fluoride was the most electronegative element in the periodic table, its removal through adsorption greatly depends on electrostatic interaction between sorbent and sorbate. Therefore, in the present study, $\mathrm{pH}$ of solution was considered as key parameter and before going to elaborate kinetic study, optimum $\mathrm{pH}$ of fluoride removal was ascertained. Furthermore, to compare the adsorption capability of SFP and CCSFP, definite amount of both of these adsorbents $(0.3 \mathrm{~g})$ were contacted with simulated fluoride solution of $10 \mathrm{mg} / \mathrm{L}$ at different $\mathrm{pH}$ conditions. $\mathrm{pH}$ of solution was maintained by adding $0.1(\mathrm{~N}) \mathrm{HCl}$ or $0.1(\mathrm{~N})$ $\mathrm{NaOH}$ and varied in the range of $1-8$. Volume of solution was $50 \mathrm{~mL}$. During experiments at $\mathrm{pH} \mathrm{3,} \mathrm{samples} \mathrm{were}$ collected after definite time intervals. The solution containing spent SFP and CCSFP were centrifuged at $5000 \mathrm{rpm}$ for $10 \mathrm{~min}$ and supernatant was collected and tested for residual fluoride concentration in solution using ion-selective fluoride electrode. It is seen that the major removal (93\%) of fluoride was obtained using CCSFP within $15 \mathrm{~min}$ and then it was gradually increased up to 98.6\%. Therefore, the contact time was fixed at $45 \mathrm{~min}$ during kinetic study. Further, maximum removal was obtained at $\mathrm{pH}$ 3. Thus, kinetic study was carried out at $\mathrm{pH}$ 3. Moreover, CCSFP showed 1.5-2 times more removal than SFP. Therefore, further studies on fluoride removal were carried out with CCSFP only. The operating parameters varied during kinetic studies include initial concentration of fluoride $(2.91-18 \mathrm{mg} / \mathrm{L})$ and adsorbent dose (2$6 \mathrm{~g} / \mathrm{L})$. Since the fluoride concentration in groundwater in West Bengal, India, lies in the rage of $1.8-20.4 \mathrm{mg} / \mathrm{L}$ (WBPHED 2006), initial fluoride concentration was chosen in the range of $2.91-18 \mathrm{mg} / \mathrm{L}$ in the present study. Furthermore, a comparative study was made to select of present initial fluoride concentration range based on the defluoridation works of other scientists (Table 2). Samples were collected after definite time intervals and analyzed for residual fluoride concentration. OFAT analysis was used during kinetic study, by varying single parameter at a time keeping others constant (Sen et al. 2017). Since fluoride reacts with borosilicate glass (Kumar et al. 2008), all the experiments in the present study were performed in 125$\mathrm{mL}$ narrow-mouth autoclavable PP bottle (TARSON, India). The reaction scheme between borosilicate glass and fluoride ion was as follows (Kumar et al. 2008):

$\mathrm{F}^{-}+\mathrm{H}_{2} \mathrm{O} \rightarrow \mathrm{HF}+\mathrm{OH}^{-}$

$\mathrm{HF}+\mathrm{SiO}_{2} \rightarrow \mathrm{H}_{2} \mathrm{O}+\mathrm{SiF}_{4}$

\section{Equilibrium study}

The adsorbate was distributed between the liquid and solid phases during adsorption process and attains maximum value on solid phase at equilibrium condition and the concentration of adsorbate in solution becomes constant at such condition (Fakhri 2017; Agarwal et al. 2016; Fakhri and Behrouz 2015b; Fakhri and Adami 2014). In the present investigation, equilibrium study was done by varying initial fluoride concentrations in the range of 2.91-22.9 mg/L keeping other variables such as adsorbent dose, volume of solution, $\mathrm{pH}$ and temperature constant at of $4 \mathrm{~g} / \mathrm{L}, 50 \mathrm{~mL}, 3$ and $25^{\circ} \mathrm{C}$, respectively. Samples were collected after $45 \mathrm{~min}$ and analyzed for residual fluoride concentration using ion-selective fluoride electrode. In next set of experiments, temperature was varied from 25 to $35{ }^{\circ} \mathrm{C}$, keeping other variables constant.

\section{Optimization of removal of fluoride using RSM}

RSM was also used to determine the optimum condition for removal of fluoride. The $(-1)$ and $(+1)$ values of three input factors namely initial concentration of fluoride, $\mathrm{pH}$ and adsorbent dose were 5 and $15 \mathrm{mg} / \mathrm{L}, 3$ and 7, and 2 and $6 \mathrm{~g} / \mathrm{L}$, respectively. The percentage removal of fluoride was considered as response. Since equilibrium was attained after only $45 \mathrm{~min}$ operation as seen from kinetic and equilibrium studies, 'time' has not been considered as input factor during optimization of such process. The batch experiments were carried out in $125-\mathrm{mL}$ autoclavable PP bottle as per the experimental design done by RSM. Volume of solution was kept $50 \mathrm{~mL}$. Samples were collected after $45 \mathrm{~min}$ and analyzed for residual fluoride concentration. The solid adsorbent obtained after adsorption of fluoride at optimum condition of fluoride removal as analyzed by RSM was collected and used for desorption study. For such studies, fluoride-loaded CCSFP samples were treated individually with water at $\mathrm{pH} 3,7$ and 11 . The flasks were kept in BOD incubator at $25^{\circ} \mathrm{C}$ and shaken at $150 \mathrm{rpm}$ for $1 \mathrm{~h}$. The supernatant obtained after centrifugation, were analyzed for desorbed fluoride content. 
Table 2 Variation of initial concentrations for removal of fluoride using different adsorbents

\begin{tabular}{|c|c|c|c|c|c|c|}
\hline $\begin{array}{l}\text { S. } \\
\text { no. }\end{array}$ & Adsorbent & $\begin{array}{l}\text { Range of initial fluoride } \\
\text { concentration }(\mathrm{mg} / \mathrm{L})\end{array}$ & $\begin{array}{l}\text { Other operating parameters } \\
\text { (optimum cond.) }\end{array}$ & $\begin{array}{l}\text { Optimum initial } \\
\text { concentration (mg/ } \\
\text { L) }\end{array}$ & $\begin{array}{l}\text { Fluoride } \\
\text { removal } \\
(\%)\end{array}$ & References \\
\hline 1 & $\begin{array}{l}\text { Aluminium-impregnated } \\
\text { potato plant ash (Al-IPPA) }\end{array}$ & $10-100$ & $\begin{array}{l}\mathrm{pH} 4.64, \mathrm{AD}=0.14 \mathrm{~g} / \mathrm{L}, \\
\text { contact time }=57 \mathrm{~min}\end{array}$ & 94.02 & 82.72 & $\begin{array}{l}\text { Ghosh et al. } \\
\text { (2016) }\end{array}$ \\
\hline 2 & Activated alumina (AA) & $5-20$ & $\begin{array}{l}\mathrm{pH} 5, \mathrm{AD}=1.5 \mathrm{~g} / \mathrm{L} \\
\mathrm{T}=40{ }^{\circ} \mathrm{C}\end{array}$ & 20 & 99.3 & $\begin{array}{l}\text { Mouelhi } \\
\text { et al. } \\
\text { (2015) }\end{array}$ \\
\hline 3 & $\begin{array}{l}\text { Raw and treated lemon leaf } \\
\text { (LLD) }\end{array}$ & $1.5-15$ & $\begin{array}{l}\mathrm{pH} 7, \text { contact } \\
\text { time }=45.97 \mathrm{~min}, \\
\mathrm{~T}=55^{\circ} \mathrm{C}\end{array}$ & 2.94 & 95.22 & $\begin{array}{l}\text { Bhaumik } \\
\text { et al. } \\
\text { (2013) }\end{array}$ \\
\hline 4 & CCSFP & $2.91-18$ & $\begin{array}{c}\mathrm{pH} 3 \text {, contact time }=45 \mathrm{~min}, \\
\mathrm{~T}=25^{\circ} \mathrm{C}, \mathrm{AD}=4 \mathrm{~g} / \mathrm{L}\end{array}$ & 2.91 & 98.3 & $\begin{array}{r}\text { Present } \\
\text { study }\end{array}$ \\
\hline
\end{tabular}

\section{Removal of excess fluoride from groundwater using CCSFP}

From literature survey it was seen that ground water in some areas at Bankura district of West Bengal, India was contaminated with fluoride (Mondal et al. 2013). Thus, groundwater was collected from several tubewells at Bankura district in West Bengal. The groundwater collected from such region was characterized in terms of its mineralogical contents with special emphasis to fluoride and other anion concentration. After characterization, groundwater was treated with CCSFP in a batch contactor for $60 \mathrm{~min}$. Removal study was performed firstly at optimum condition as analyzed by RSM. Adsorbent dose and initial $\mathrm{pH}$ were kept as $2 \mathrm{~g} / \mathrm{L}$ and 3.5, respectively. However, in another study, the removal of fluoride from groundwater was done at its native $\mathrm{pH}(8.8)$. The samples were collected after definite time intervals and analyzed for residual fluoride concentration.

\section{Results and discussion}

\section{Application of RSM for preparation of CCSFP}

Three input variables, viz. weight ratio of calcium chloride to SFP, temperature and time were varied according to the design as specified by the Design Expert Software 8.0.6 and percentage removal of fluoride by the calcium-impregnated adsorbent samples prepared at different operating conditions, were considered as the response or output variable. They are shown in Table 1 . The responses were analyzed using ANOVA (Table 3). Maximum and minimum values of response obtained were 97.91 and $23.33 \%$, respectively, with a mean value of $77.07 \%$. The ratio of maximum to minimum value of response was 4.19 . Since this value was lower than 10, no transformation was required. As suggested by the software, quadratic model was used to fit the responses. The final equation obtained in terms of coded factors is given below:

$$
\begin{aligned}
R_{1}= & 94.51-2.34 \times A+20.56 \times B-11.02 \times C+3.41 \\
& \times A B-1.72 \times A C+12.97 \times B C+1.29 \times A^{2} \\
& -9.88 \times B^{2}-16.94 \times C^{2},
\end{aligned}
$$

where $R_{1}$ is the response in terms of removal of fluoride $(\%), A$ is the time of impregnation (h), $B$ is the temperature of impregnation $\left({ }^{\circ} \mathrm{C}\right)$ and $C$ the weight ratio of calcium chloride and SFP. The statistical parameters, viz. $R^{2}, R_{\text {Adj }}^{2}$ and $R_{\text {Pred }}^{2}$ were obtained as $0.9751,0.9527$ and 0.8048 , respectively.

$p$ value lower than 0.0001 implied that the model was significant (Table 3). The conjugated effect of carbonization temperature and weight ratio of calcium chloride and SFP $(B C)$ had significant role on removal of fluoride. Thus, the response surface diagram of the combined effect $(B C)$ was analyzed as shown in Fig. 1. Fluoride removal decreased from 71.32 to $24.68 \%$ when ratio of calcium chloride and SFP was increased from 2.5 to 7.5 at constant temperature of $450{ }^{\circ} \mathrm{C}$. This might be due to the increased chloride concentration on prepared adsorbent at higher impregnation ratio, which might have repelled the incoming fluoride ion onto the surface of the adsorbent. Similar observations were made by Habuda-Stanić et al. (2014). However, at $550{ }^{\circ} \mathrm{C}$, the negative effect of high impregnation ratio was found to be negligible small. At constant temperature of $550{ }^{\circ} \mathrm{C}$, when weight ratio of calcium chloride and SFP was increased from 2.5 to 7.5 , fluoride removal changed from 87.05 to $90.22 \%$ indicating constant fluoride removal. This might be due to the excellent 
Table 3 Analysis of variance table for CCSFP preparation

\begin{tabular}{|c|c|c|c|c|c|}
\hline Source & Sum of squares & $d f$ & Mean square & $F$ value & $\begin{array}{l}p \text { value } \\
\text { Prob }>F\end{array}$ \\
\hline Model & 14377.08 & 9 & 1597.45 & 43.50 & $<0.0001$ (significant) \\
\hline$A$-time & 78.04 & 1 & 78.04 & 2.13 & 0.1756 \\
\hline$B$-temperature & 5803.64 & 1 & 5803.64 & 158.06 & $<0.0001$ \\
\hline$C$-ratio & 1671.81 & 1 & 1671.81 & 45.53 & $<0.0001$ \\
\hline$A B$ & 97.97 & 1 & 97.97 & 2.67 & 0.1334 \\
\hline$A C$ & 21.24 & 1 & 21.24 & 0.58 & 0.4645 \\
\hline$B C$ & 1328.40 & 1 & 1328.40 & 36.18 & 0.0001 \\
\hline$A^{2}$ & 24.48 & 1 & 24.48 & 0.67 & 0.4333 \\
\hline$B^{2}$ & 1402.48 & 1 & 1402.48 & 38.19 & 0.0001 \\
\hline$C^{2}$ & 4199.63 & 1 & 4199.63 & 114.37 & $<0.0001$ \\
\hline Residual & 367.19 & 10 & 36.72 & & \\
\hline Lack of fit & 367.19 & 5 & 73.44 & & \\
\hline Pure error & 0.000 & 5 & 0.000 & & \\
\hline Cor total & $14,744.27$ & 19 & & & \\
\hline
\end{tabular}



Fig. 1 Response surface diagram of conjugated effect of temperature of carbonization and weight ratio of calcium chloride and SFP for preparation of CCSFP

carbonization of SFP at $550{ }^{\circ} \mathrm{C}$ which subdued the negative effect of higher impregnation ratio.

In order to make the process cost-effective, criteria of optimization were set as: time of impregnation: minimum, temperature of impregnation: in range, weight ratio of calcium chloride and SFP: minimum and removal of fluoride: maximum. The optimum conditions obtained was as follows-temperature of carbonization: $500{ }^{\circ} \mathrm{C}$, weight ratio of calcium chloride and SFP: 2.5 and time of carbonization: $60 \mathrm{~min}$. The sample prepared at the present condition was termed as calcium-impregnated carbonized sal flower petals (CCSFP) and was used for further fluoride removal experiments.

\section{Characterization of SFP and CCSFP}

SFP and CCSFP were characterized in terms of its solid density, bulk density, moisture content, volatile matter, total fixed carbon and ash content following standard protocol (CEFIC 1986). The values of the above parameters are shown in Table 4. From the table, it was seen that the solid density of SFP $\left(159.35 \mathrm{~kg} / \mathrm{m}^{3}\right)$ was lower than CCSFP $\left(899.8 \mathrm{~kg} / \mathrm{m}^{3}\right)$. The volatile matter content of SFP (66.9\%) was more than that of CCSFP (52.53\%), while CCSFP contains more amount of ash $(6.12 \%)$ than SFP $(5.02 \%)$. It was obvious since SFP was a biomaterial while CCSFP was prepared by carbonization of its native form. During carbonization volatile matters are reduced and compact carbon mass is formed (Bhaumik and Mondal 2016). Solid density of inorganic matter present in ash was always more than the pure carbonaceous component (Karthikeyan and Elango 2008). Total fixed carbon of SFP (28\%) was lower than CCSFP (34.94\%), which indicated that the higher efficiency of CCSFP, than SFP as carbonaceous adsorbent. Furthermore, the lower ash content of the sample indicated the presence of lower amount of inorganic material indicating its suitability as adsorbent (Zhang et al. 2015). From Table 4, it was seen that $\mathrm{pH}_{\mathrm{zpc}}$ of SFP and CCSFP were approximately 7.0 and 8.2 , respectively, which indicated the change of some functional groups on surface due to activation. Therefore, the solution $\mathrm{pH}$ value lower than 7.0 and 8.2 suggested the presence of positively charged ions on the surfaces, which helped to 
Table 4 Characterization of CCSFP as determined

\begin{tabular}{llc}
\hline Parameter & SFP & CCSFP \\
\hline Solid density $\left(\mathrm{kg} / \mathrm{m}^{3}\right)$ & 159.3 & 899.8 \\
Bulk density $\left(\mathrm{kg} / \mathrm{m}^{3}\right)$ & 125 & 117.98 \\
Moisture content $(\%)$ & 8 & 6.41 \\
Ash content $(\%)$ & 5.02 & 6.12 \\
Volatile matter $(\%)$ & 66.9 & 52.53 \\
Total fixed carbon $(\%)$ & 28 & 34.94 \\
BET surface Area $\left(\mathrm{m}^{2} / \mathrm{g}\right)$ & - & 227.066 \\
pHzpc & 7.0 & 8.2 \\
\hline
\end{tabular}


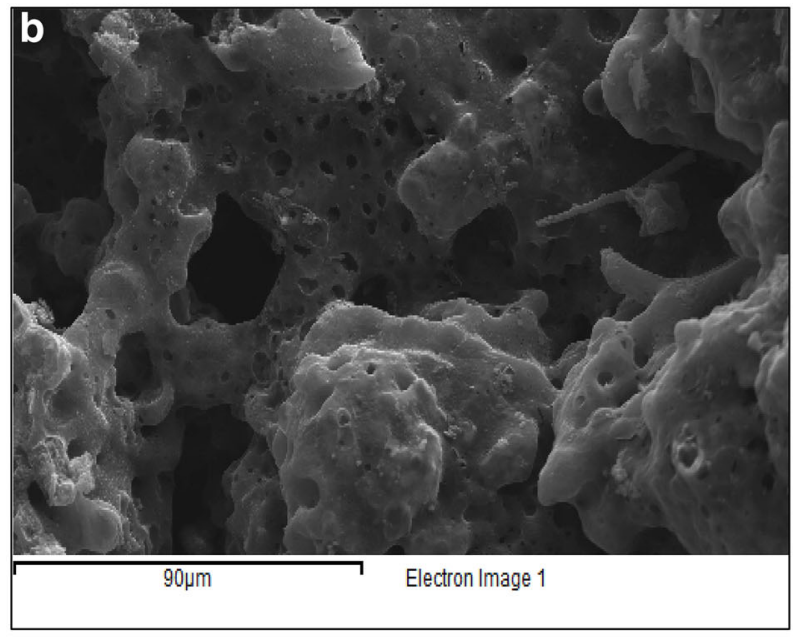

d

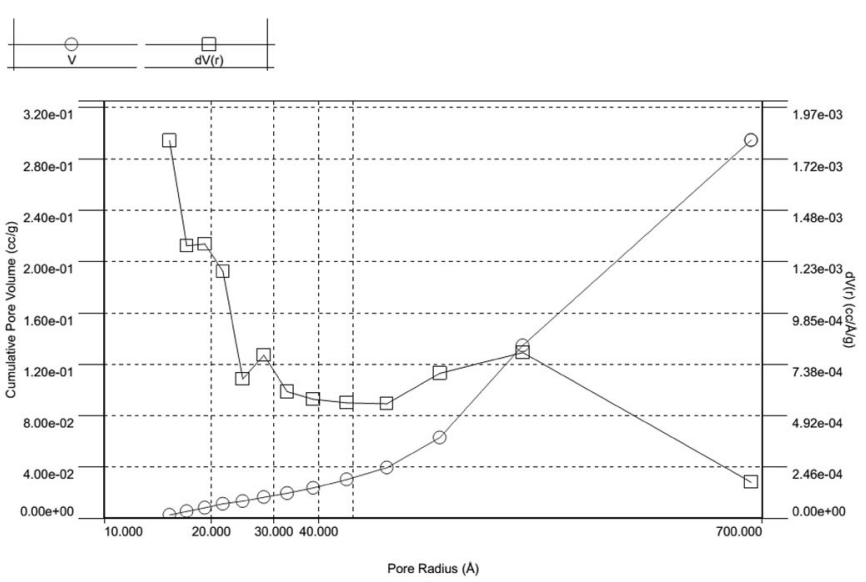

Fig. 2 Scanning electron micrograph of a CCSFP and $\mathbf{b}$ fluoride-loaded CCSFP. $\mathbf{c}$ Nitrogen adsorption-desorption isotherm curve of CCSFP. d Pore size distribution of CCSFP

interact with negative ions like fluoride in solution (Bhaumik and Mondal 2016).

SEM images of CCSFP and fluoride-loaded CCSFP are shown in Fig. 2a, b, respectively. It is seen from the figures that both adsorbents looked like heterogeneous lamellar structure. Both of the surfaces were found to be rough and had many small pores. BET surface area of CCSFP has been found to be $227.066 \mathrm{~m}^{2} / \mathrm{g}$ which was greater than that of other modified activated carbons (Chakrapani et al. 2010; Kumar et al. 2008). BET measurements of CCSFP showed that it had mesoporous structure with irregular pores. Nitrogen adsorption- 
desorption isotherm with pore size distribution (Fig. 2c, d) were recorded to calculate the specific surface area and porosity of CCSFP. The pore volume and the specific surface area were found to be $0.285 \mathrm{~g} / \mathrm{cc}$ and $60.965 \mathrm{~m}^{2} / \mathrm{g}$, respectively. Nitrogen adsorption-desorption also revealed the mesoporous nature of the present adsorbent. The size distribution of the pores was in the range of 15.37-1013.84 $\AA$ (1.537-101.384 nm). The morphology and irregularity of pores is clearly seen in BJH (Barrett-Joyner-Halenda) plot (Fig. 2d). EDX study of SFP, CCSFP and fluorideloaded CCSFP is shown in Fig. 3a, b and c, respectively. SFP contained $60.16 \%$ carbon (C), 37.9\% oxygen (O), $0.34 \%$ magnesium $(\mathrm{Mg}), 0.43 \%$ sulphur $(\mathrm{S})$ and $1.18 \%$ potassium (K). CCSFP contained $78.10 \%$ carbon (C), $8.59 \%$ oxygen $(\mathrm{O}), 1.15 \%$ phosphorus $(\mathrm{P}), 5.38 \%$ chlorine $(\mathrm{Cl})$ and $6.78 \%$ calcium $(\mathrm{Ca})$. Presence of higher amount of $\mathrm{C}$ and $\mathrm{Ca}$ in CCSFP in comparison to SFP indicated successful Ca-impregnation and carbonization of sal flower petal. After treatment with fluoride, CCSFP contained $3.05 \%$ fluoride $(\mathrm{F}), 77.96 \%$ carbon $(\mathrm{C}), 12.76 \%$ oxygen (O), $0.41 \%$ phosphorus $(\mathrm{P}), 0.98 \%$ chlorine $(\mathrm{Cl})$ and $4.84 \%$ calcium $(\mathrm{Ca})$, which indicated the fluoride sorption on adsorbent surface. FTIR studies of CCSFP (Fig. 4a) and fluoride-loaded CCSFP (Fig. 4b) were done to observe the changes in spectra due to introduction of fluoride in the later case. Wave numbers were varied in the range of $400-4500 \mathrm{~cm}^{-1}$. The characteristics bonds such as $-\mathrm{C}-\mathrm{Cl}$ (stretch, strong), =C-H (bending, strong), $-\mathrm{C}-\mathrm{H}$ (bending, variable) and $\mathrm{N}-\mathrm{H}$ (amines, medium) functional groups were seen at the wave number of 755, 1361, 1607 and $3434 \mathrm{~cm}^{-1}$, respectively. However, FTIR graph of fluoride-loaded CCSFP showed some different spectra. The presence of strong $\mathrm{C}-\mathrm{F}$ bond at the wave number of $1253 \mathrm{~cm}^{-1}$ (Silverstein et al. 1981) indicated the adsorption of fluoride on the Ca-impregnated carbonized adsorbent. The characteristic bonds such as $\mathrm{C}=\mathrm{O}\left(1796 \mathrm{~cm}^{-1}\right.$, stretch, strong), $\mathrm{C}-\mathrm{H}\left(2922 \mathrm{~cm}^{-1}\right.$, stretch, strong) and $\mathrm{N}-\mathrm{H}$ $\left(3434 \mathrm{~cm}^{-1}\right.$, amines) were seen in fluoride-loaded CCSFP. Therefore, the proof of fluoride adsorption onto CCSFP was primarily established.

\section{Fluoride removal using SFP}

\section{Effect of $p H$}

In case of SFP, when $\mathrm{pH}$ was increased from 1 to 3 , fluoride removal increased from 50.5 to $59.3 \%$ and when $\mathrm{pH}$ was increased from 3 to 8 , fluoride removal gradually decreased from 59.3 to $27 \%$ (Fig. 5). For CCSFP, it was seen that, as $\mathrm{pH}$ was increased from 1 to 3 , fluoride removal increased from 93.8 to $98.7 \%$. However, when $\mathrm{pH}$ was increased from 3 to 8 , removal decreased from 98.7 to $79.02 \%$ (Fig. 5). Such trend of removal might be attributed


Fig. 3 EDX of a SFP, $\mathbf{b}$ CCSFP and $\mathbf{c}$ fluoride-loaded CCSFP

to the positive charged surface of both SFP and CCSFP at acidic $\mathrm{pH}$ conditions to which fluoride got easily bound. Similar observation was made by Ganvir and Das (2011) and Yadav et al. (2013). $\mathrm{pH}_{\mathrm{zpc}}$ of SFP and CCSFP were found to be 7.0 and 8.2, respectively. This implied that solution $\mathrm{pH}$ less than $\mathrm{pH}_{\mathrm{zpc}}$ was the favorable condition for the fluoride removal process as positively charged surface could easily bind the negatively charged fluoride ions. In the present study, $\mathrm{pH} 3$ was thus chosen as the optimum $\mathrm{pH}$ 

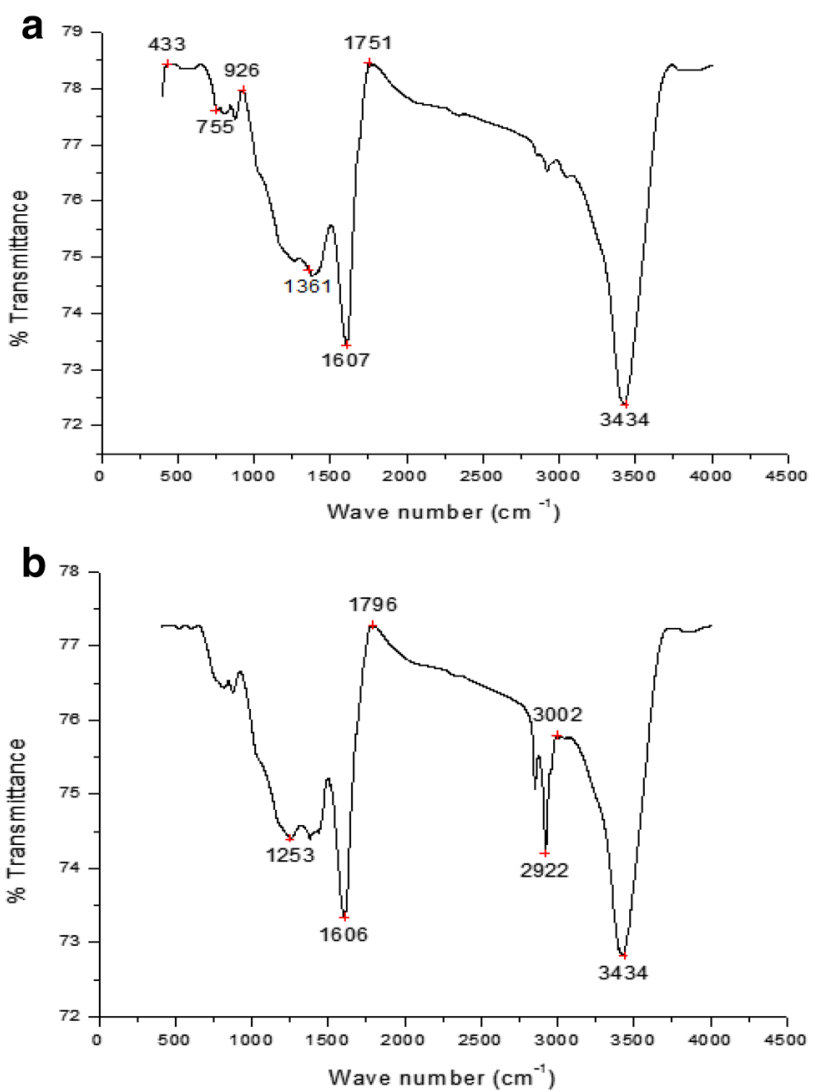

Fig. 4 FTIR spectra of a CCSFP and b fluoride-loaded CCSFP

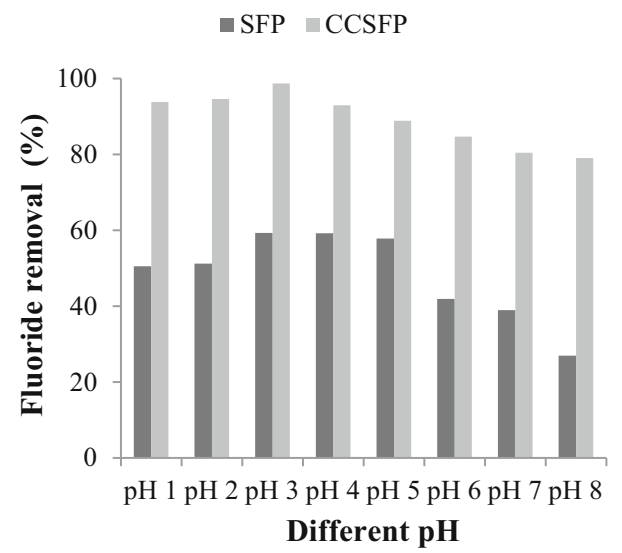

Fig. 5 Effect of initial solution pH on fluoride removal for SFP and CCSFP

for removal of fluoride. Similar observations were made by Bhaumik and Mondal (2016). They reported the higher fluoride adsorption capacity at lower $\mathrm{pH}\left(<\mathrm{pH}_{\mathrm{zpc}}\right)$. In Fig. 5, it was also seen that adsorptive capability of CCSFP was about 1.5-2 times greater than that of SFP under identical condition. Therefore, it can be stated that calcium impregnation enhanced the fluoride removal in case of CCSFP. Bhaumik et al. (2013) showed that the maximum adsorption capacity of fluoride onto calcium-modified lemon leaf surface was higher $(38.46 \mathrm{mg} / \mathrm{g})$ than raw lemon leaf powder $(7.63 \mathrm{mg} / \mathrm{g})$. Since much more removal was achieved with CCSFP, further studies on fluoride removal was done with CCSFP only.

\section{Kinetic study}

To assess the mechanism of adsorptive removal of fluoride using CCSFP and to evaluate the kinetic variables, a detailed kinetic study was carried out. The variation of percentage removal of fluoride with time considering different initial concentrations of fluoride as variable is shown in Fig. 6a. It was observed that, major removal was achieved within $5 \mathrm{~min}$ and the system attained equilibrium in $45 \mathrm{~min}$, with $4 \mathrm{~g} / \mathrm{L}$ adsorbent dose and $\mathrm{pH} 3$. The initial portion of curve represents the high adsorption of the fluoride ions on to adsorbents. The second stage shows the slow uptake of fluoride ions. Finally, saturation of all active sites on the adsorbents surface and attainment of equilibrium conditions have been seen (Yadav et al. 2013). The
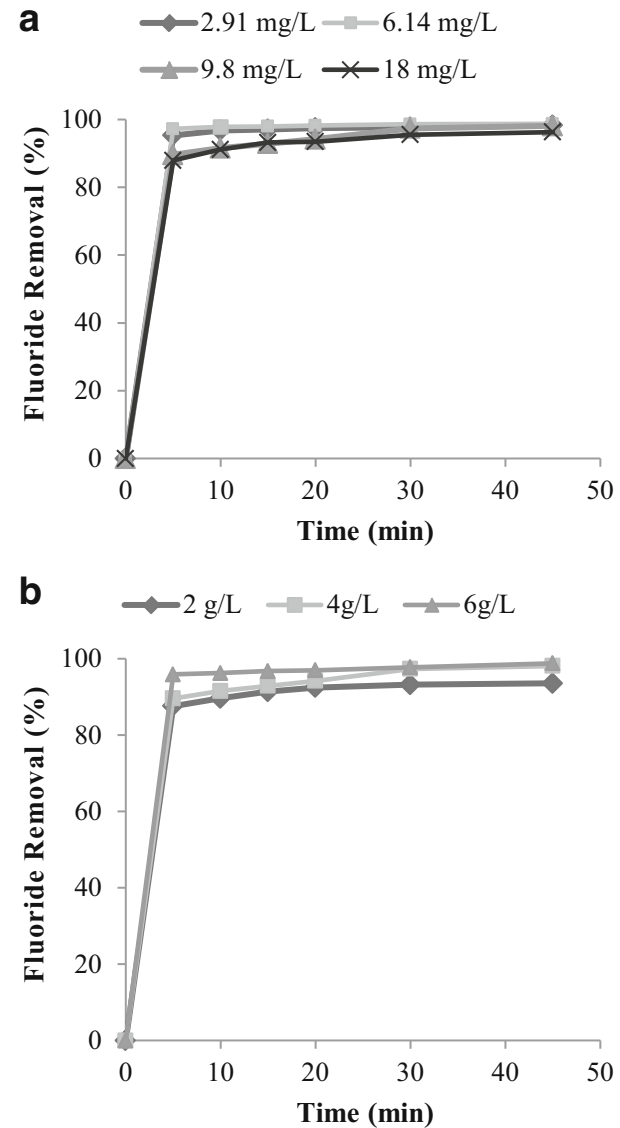

Fig. 6 a Kinetic study at different initial fluoride concentrations (adsorbent dose: $4 \mathrm{~g} / \mathrm{L}$, volume of solution: $50 \mathrm{~mL}, \mathrm{pH}: 3$ and temperature $25^{\circ} \mathrm{C}$ ). b Kinetic study at different adsorbent doses (initial fluoride concentration: $10.4 \mathrm{mg} / \mathrm{L}$, volume of solution: $50 \mathrm{~mL}$, pH: 3 and temperature $25^{\circ} \mathrm{C}$ ) 
percentage removal of fluoride decreased with the increase of initial fluoride concentrations. About 98.3 and $96.3 \%$ of removal were obtained for 2.91 and $18 \mathrm{mg} / \mathrm{L}$ of initial fluoride concentrations, respectively. This might be due to competitive inhibition between the excess fluoride ions present in the solution and the limitation of the available binding sites over adsorbent surface (Hernández-Montoya et al. 2012). Kinetic study was also done at different adsorbent doses ranging from 2 to $6 \mathrm{~g} / \mathrm{L}$ at initial fluoride concentration of $10.4 \mathrm{mg} / \mathrm{L}, \mathrm{pH} 3$ and temperature $25^{\circ} \mathrm{C}$. It is seen from Fig. $6 \mathrm{~b}$ that, as adsorbent dose was increased from 2 to $6 \mathrm{~g} / \mathrm{L}$, removal increased from 93.5 to $98.8 \%$, after $45 \mathrm{~min}$ of contact time. This might be attributed to the availability of larger number of adsorption sites for the same amount of fluoride ions (Biswas et al. 2016; Zhang et al. 2015). $\mathrm{CaF}_{2}$ is a very stable compound. Researches are made to impregnate $\mathrm{Ca}^{2+}$ onto adsorbent for enhanced removal of fluoride from solution (Mohapatra et al. 2009; Bhaumik et al. 2012; Hernández-Montoya et al. 2012). In the present study, $\mathrm{Ca}^{2+}$ was impregnated onto the surface of adsorbent during carbonization process. Fluoride ions $\left(\mathrm{F}^{-}\right)$in solution got attracted by the cations of $\mathrm{Ca}^{2+}$ and attached with it by electrostatic interaction. Thus, the binding of $\mathrm{Ca}^{2+}$ with $\mathrm{F}^{-}$is the rate limiting step and the process is not diffusion rate controlled, but reaction rate controlled. Kinetic data were fitted to different kinetic models (Fig. 7a-f), viz. Lagergren first-order, Ho pseudosecond-order and Morris-Weber intra-particle diffusion models. It is seen that the kinetic data fitted best to Ho pseudo-second-order model with $R^{2}$ value of $0.999-1$. The values of kinetic variables are shown in Table 5. Similar observation was made by several scientists (Viswanathan et al. 2009; Chakrapani et al. 2010). The experimental $q_{e}$ matched quite well with simulated data for Ho pseudosecond order. From Table 5, it was seen that Ho pseudosecond-order constant rate $\left(k_{2}\right)$ was higher at lower initial concentration and at higher adsorbent dose. It was quite obvious that at lower initial concentration, fluoride ion could easily be adsorbed on the surface of CCSFP and the rate of removal was high. It signified that the defluoridation process using CCSFP was not mass transfer controlled, but kinetically controlled. Similarly, at higher adsorbent dose, fluoride ion could bind with active sites easily due to availability of more adsorption sites.

\section{Equilibrium study}

Equilibrium study was done at different initial fluoride concentrations, viz. 2.91, 6.14, 14.6 and $22.9 \mathrm{mg} / \mathrm{L}$ at an adsorbent dose of $4 \mathrm{~g} / \mathrm{L}, \mathrm{pH} \mathrm{3}$, contact time of $45 \mathrm{~min}$ and at $25{ }^{\circ} \mathrm{C}$. The linearized plot of Langmuir, linearized plot of Freundlich and plot of linear isotherm are shown in
Fig. 8a, b and c, respectively. Equilibrium data were found to fit well to Freundlich isotherm model (Fig. 8b). Adsorption capacity was obtained as $5.4645 \mathrm{mg} / \mathrm{g}$. The values of equilibrium parameters are shown in Table 6. A comparative study on fluoride sorption capacities showed that CCSFP had better fluoride removal capacity than that of other adsorbents (Table 7). Since the sal flower petals are inexpensive and abundant in nature, the usage of CCSFP can be a good option to remove fluoride efficiently from drinking water. Heat of adsorption is a characteristic property of the adsorption process and more specifically to type of adsorption and the extent of adsorption. The wellknown van't Hoff's equation relates the change in the equilibrium constant $\left(K_{\mathrm{L}}\right)$ of a chemical reaction to the change in temperature $(T)$ for standard enthalpy change $(\Delta H)$ of the process. In the present study, the adsorption process was found to be exothermic having negative heat of adsorption $(\Delta H) \mathrm{kJ} / \mathrm{mol}$ as obtained from van't Hoff's equation (Table 8). The lower removal of fluoride at higher temperature substantiated the present inference. Moreover, the reciprocal nature of $K_{\mathrm{L}}$ with temperature reconfirmed the exothermic nature of adsorption process (Table 8). The other thermodynamic parameters like change in entropy $(\Delta S)$ and Gibbs free energy $(\Delta G)$ are also reported in Table 8 . This study suggested that adsorption was favored at lower temperature.

\section{Optimization of removal of fluoride using RSM}

During optimization of removal of fluoride using RSM, three parameters namely $\mathrm{pH}$, adsorbent dosage and initial concentration were chosen as input factors since adsorption of fluoride mainly depends on such factors. The experiments were performed as per the experimental design done by RSM (Table 9), the removal of fluoride was determined and placed at the corresponding position in Table 9. The responses were analyzed by ANOVA. p value lower than 0.0001 implied that the model was significant (Table 10). As suggested by the software, quadratic model was used to fit the experimental data. The final equation obtained in terms of coded factors is given below:

$$
\begin{aligned}
R_{1}^{\prime}= & 91.99-4.07 \times A^{\prime}+0.059 \times B^{\prime}-2.79 \times C^{\prime}+1.6 \\
& \times A^{\prime} \times B^{\prime}+0.53 \times A^{\prime} \times C^{\prime}-1.47 \times B^{\prime} \times C^{\prime}-0.86 \\
& \times A^{\prime 2}-1.6 \times B^{\prime 2}-1.22 \times C^{\prime 2},
\end{aligned}
$$

where $R_{1}^{\prime}$ is the response in terms of removal of fluoride $(\%) ; A^{\prime}$ is the initial concentration $(\mathrm{mg} / \mathrm{L}) ; B^{\prime}$ is the adsorbent dose $(\mathrm{g} / \mathrm{L})$ and $C^{\prime}, \mathrm{pH}$ of the solution.

The higher values of statistical parameters, viz. $R^{2}(0.9691), R_{\text {Adj }}^{2}(0.9413)$ and $R_{\text {Pred }}^{2}(0.7514)$ signified the good fitting of experimental data to model. The model also 
a

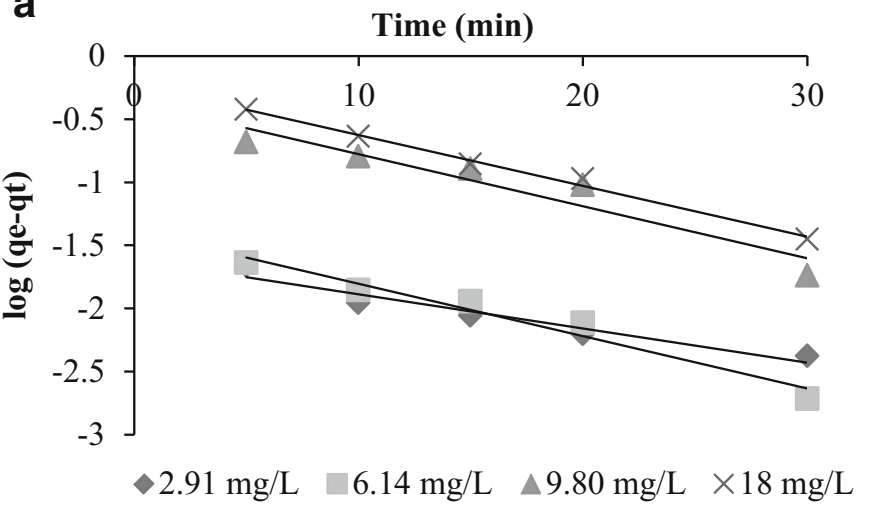

b $\quad 2.91 \mathrm{mg} / \mathrm{L} \quad 6.14 \mathrm{mg} / \mathrm{L} \quad \Delta 9.80 \mathrm{mg} / \mathrm{L} \quad \times 18 \mathrm{mg} / \mathrm{L}$

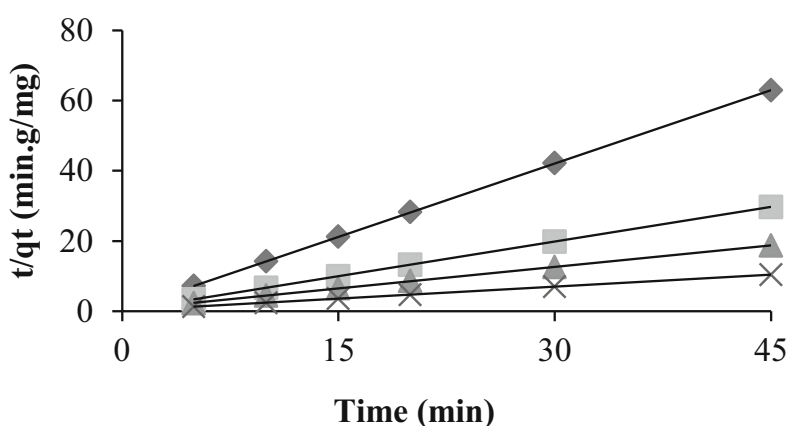

C $\diamond 2.91 \mathrm{mg} / \mathrm{L} \quad 6.14 \mathrm{mg} / \mathrm{L} \quad \Delta 9.80 \mathrm{mg} / \mathrm{L} \quad \times 18 \mathrm{mg} / \mathrm{L}$

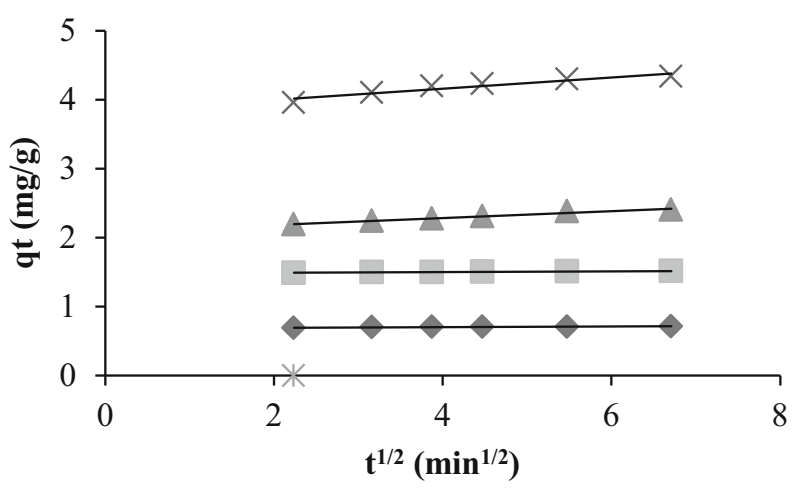

Fig. 7 a Lagergren first-order model when initial concentration was varied. b Pseudo-second-order kinetic model when initial concentration was varied. c Morris-Weber intra-particle diffusion model when initial concentration was varied. $\mathbf{d}$ Lagergren first-order model when

showed that $R_{\text {Pred }}^{2}$ was in reasonable agreement with $R_{\text {Adj }}^{2}$ value. As analyzed by ANOVA (Table 10), it was seen that $A$ (initial concentration of fluoride), $C(\mathrm{pH}), A B$ (conjugate effect of initial concentration of fluoride and adsorbent dose) and $B C$ (conjugate effect of adsorbent dose and $\mathrm{pH}$ ) were significant model terms (Table 10). The conjugate effect of adsorbent dose and initial concentration on percentage removal of fluoride is shown in Fig. 9a. When
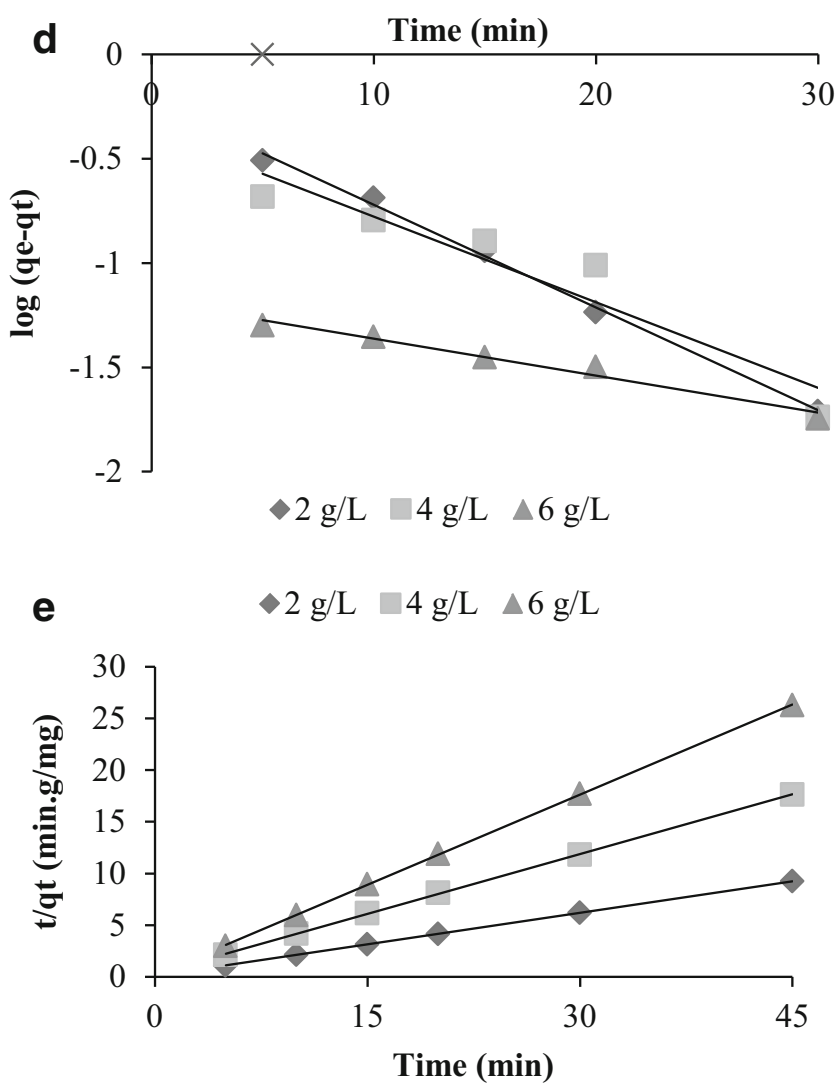

f

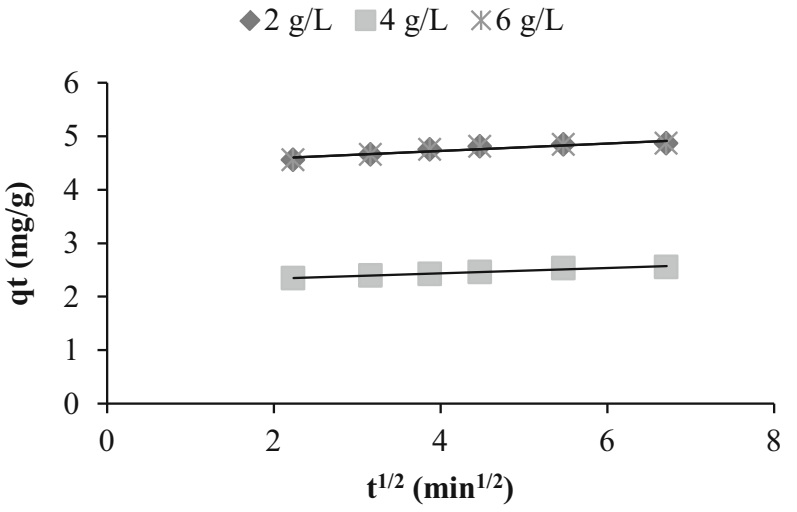

adsorbent dose was varied. e Pseudo-second-order kinetic model when adsorbent dose was varied. f Morris-Weber intra-particle diffusion model when adsorbent dose was varied

adsorbent dose increased from 2 to $5 \mathrm{~g} / \mathrm{L}$ at initial fluoride concentration of $15 \mathrm{mg} / \mathrm{L}$, the removal increased from 83.8 to $87.1 \%$ and at $5 \mathrm{mg} / \mathrm{L}$, the removal remained almost same as 92.57 and $92.04 \%$, respectively. The higher removal at higher adsorbent dose was expected as seen in case of initial concentration of $15 \mathrm{mg} / \mathrm{L}$. However, at lower initial concentration, the removal of fluoride was almost same. This might be due to comparatively excess amount 
Table 5 Values of kinetic parameters

\begin{tabular}{|c|c|c|c|c|c|c|c|c|c|}
\hline \multirow[t]{2}{*}{ Parameter } & \multirow{2}{*}{$\begin{array}{l}\text { Exp. value } \\
q_{\mathrm{e}}\end{array}$} & \multicolumn{3}{|c|}{$\begin{array}{l}\text { Pseudo-first-order model } \\
\log \left(q_{\mathrm{e}}-q_{\mathrm{t}}\right)=\log q_{\mathrm{e}}-k_{1} t\end{array}$} & \multicolumn{3}{|c|}{$\begin{array}{l}\text { Pseudo-second-order model } \\
\frac{t}{q_{t}}=\frac{1}{k_{2}} \times \frac{1}{q_{\mathrm{e}}^{2}}+\frac{t}{q_{\mathrm{e}}}\end{array}$} & \multicolumn{2}{|c|}{$\begin{array}{l}\text { Intra-particle diffusion model } \\
q_{t}=k_{\mathrm{p}} t^{\frac{1}{2}}\end{array}$} \\
\hline & & $k_{1}$ & $q_{\mathrm{e}}$ & $R^{2}$ & $k_{2}$ & $q_{e}$ & $R^{2}$ & $k_{p}$ & $R^{2}$ \\
\hline \multicolumn{10}{|c|}{ Initial fluoride concentration (mg/L) } \\
\hline 2.91 & 0.707 & 0.0830 & 0.0243 & 0.935 & 0.1064 & 0.7179 & 1 & 0.004 & 0.879 \\
\hline 6.14 & 1.292 & 0.1259 & 0.0410 & 0.959 & 0.0237 & 1.5198 & 1 & 0.005 & 0.940 \\
\hline 9.80 & 2.185 & 0.1259 & 0.4315 & 0.902 & 0.0076 & 2.4510 & 0.999 & 0.049 & 0.969 \\
\hline 18 & 3.957 & 0.1228 & 0.5957 & 0.992 & 0.0056 & 4.4053 & 1 & 0.081 & 0.905 \\
\hline \multicolumn{10}{|c|}{ Adsorbent dose $(\mathrm{g} / \mathrm{L})$} \\
\hline 2 & 3.653 & 0.1505 & 0.5916 & 0.996 & 0.0071 & 4.9261 & 1 & 0.07 & 0.880 \\
\hline 4 & 1.993 & 0.1259 & 0.4315 & 0.898 & 0.0076 & 2.5974 & 0.999 & 0.049 & 0.97 \\
\hline 6 & 1.333 & 0.0522 & 0.0653 & 0.973 & 0.0296 & 1.7212 & 0.998 & 0.011 & 0.979 \\
\hline
\end{tabular}
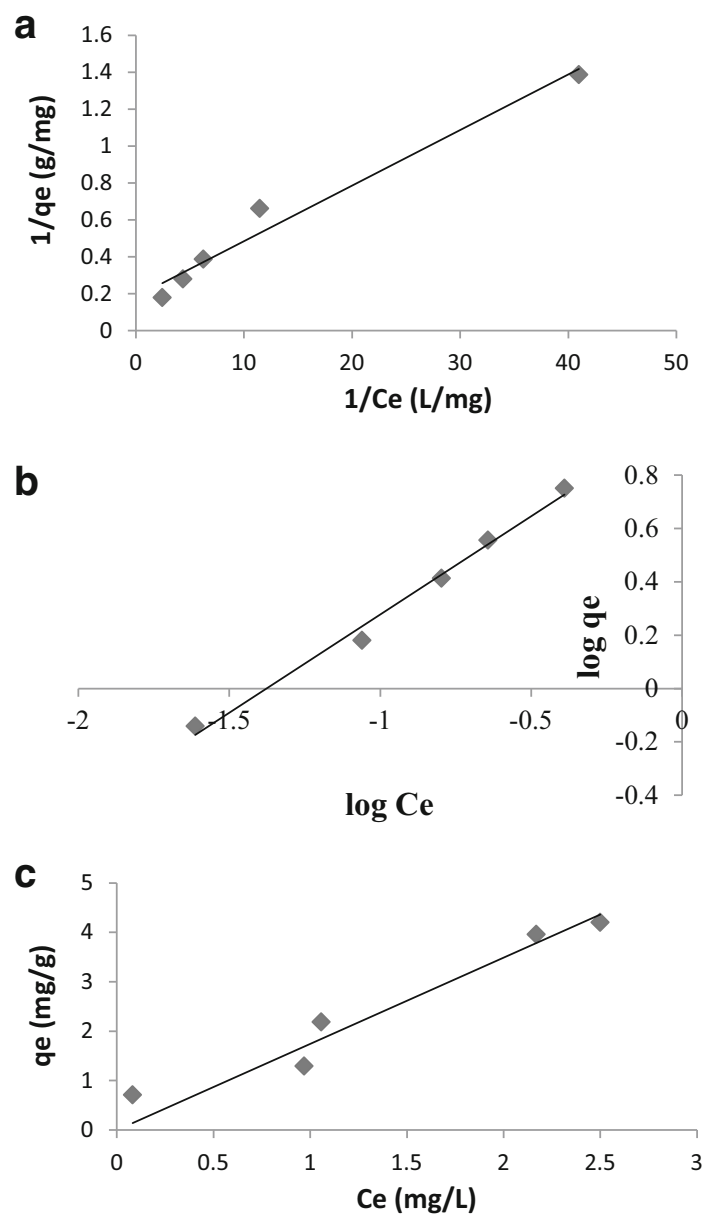

Fig. 8 a Langmuir isotherm model. b Freundlich isotherm model. c Linear isotherm model

of adsorbent at such initial concentration of fluoride. The conjugate effect of adsorbent dose and $\mathrm{pH}$ on percentage removal of fluoride is shown in Fig. 9b. When $\mathrm{pH}$ increased from 3 to 6.5 at adsorbent dose of $2 \mathrm{~g} / \mathrm{L}$, the removal decreased from 90.4 to $87.8 \%$ and at $5 \mathrm{~g} / \mathrm{L}$, the removal decreased from 93.47 to $85.4 \%$, respectively. During the experiments to see the effect of $\mathrm{pH}$, the maximum removal was obtained at $\mathrm{pH} 3$ (Fig. 5). The same trend was seen in RSM analysis (Fig. 9c). The conjugate effect of initial concentration and $\mathrm{pH}$ on percentage removal of fluoride is shown in Fig. 9c. When $\mathrm{pH}$ increased from 3 to 6.5 at $5 \mathrm{mg} / \mathrm{L}$ initial concentration, the removal decreased from 97.2 to $90.6 \%$ and at $15 \mathrm{mg} / \mathrm{L}$, the removal decreased from 88.1 to $83.6 \%$, respectively. During optimization, the constraints were fixed in such a manner that the removal process becomes cost-effective. Therefore, adsorbent dose was set as 'minimum' and $\mathrm{pH}$ was set as 'in range'. Since the concentration of fluoride varied in groundwater, the criterion for initial concentration was set as 'in range'. The optimal condition as specified by RSM was initial concentration: $5 \mathrm{mg} / \mathrm{L}, \mathrm{pH}: 3.5$ and adsorbent dose: $2 \mathrm{~g} / \mathrm{L}$. Predicted removal at this condition was $95.8 \%$. Experimental removal (94.5\%) matched quite well with the predicted one.

\section{Desorption study}

After treatment of fluoride-loaded adsorbent at different $\mathrm{pH}$ conditions, the desorption of fluoride was found to be $11.96,13$ and $25 \%$ at $\mathrm{pH} 3,7$ and 11 , respectively. The higher desorption at alkaline solution might be due to leaching of bound fluoride ions from adsorbent surface. Similar types of fluoride desorption pattern from calcareous soil and banana peel dust were reported by Mondal et al. (2012) and Bhaumik and Mondal (2016). 
Table 6 Values of equilibrium parameters

\begin{tabular}{ll}
\hline Adsorption isotherm model & Constants \\
\hline Langmuir model & $R^{2}=0.972$ \\
$q_{\mathrm{e}}=\frac{q_{\mathrm{m}} K_{\mathrm{L}} C_{\mathrm{e}}}{1+K_{\mathrm{L}} C_{\mathrm{e}}}$ & $q_{\mathrm{m}}=5.4645$ \\
& $K_{\mathrm{L}}=0.1017$ \\
Freundlich model & $R^{2}=0.989$ \\
$q_{\mathrm{e}}=K_{\mathrm{F}} C_{\mathrm{e}}^{1 / n}$ & $1 / n=0.736$ \\
Linear model & $K_{\mathrm{F}}=0.1721$ \\
$q_{\mathrm{e}}=K C_{\mathrm{e}}$ & $K=1.802$ \\
\hline
\end{tabular}

\section{Removal of fluoride from untreated groundwater by CCSFP}

The physico-chemical properties of untreated groundwater sample, collected directly from a fluoride-contaminated tube well (64 feet deep) at Bankura district, were determined following standard protocol (Eugene et al. 2012). The untreated groundwater was characterized as $\mathrm{pH}: 8.8$, TDS: $420 \mathrm{mg} / \mathrm{L}$, total hardness: $260 \mathrm{mg} / \mathrm{L}$, total alkalinity: $310 \mathrm{mg} / \mathrm{L}$, chloride: $85 \mathrm{mg} / \mathrm{L}$ and fluoride: $7.5 \mathrm{mg} / \mathrm{L}$. As seen from OFAT analysis, the optimum conditions were: initial fluoride concentration $2.91 \mathrm{mg} / \mathrm{L}, \mathrm{pH} 3$, adsorbent dose $4 \mathrm{~g} / \mathrm{L}$ with a removal of $98.5 \%$ fluoride. It can be stated that though slightly more removal was achieved at optimum condition, analyzed through OFAT than through RSM. Hence, the untreated groundwater was contacted with CCSFP in a batch contactor with $4 \mathrm{~g} / \mathrm{L}$ adsorbent dose at $25{ }^{\circ} \mathrm{C}$ at two $\mathrm{pH}$ conditions namely groundwater own $\mathrm{pH}$ (8.8) and optimum $\mathrm{pH}$ as analyzed by OFAT (3.0). From Fig. 10, it can be seen that $\mathrm{pH}$ had major effect on the removal efficacy of CCSFP. After $60 \mathrm{~min}$ of contact time, 40.8 and $80.4 \%$ removal were obtained when fluoridecontaminated groundwater was contacted with CCSFP at
Table 8 Values of thermodynamic parameters

\begin{tabular}{lllll}
\hline $\begin{array}{l}\text { Temperature } \\
(\mathrm{K})\end{array}$ & $\begin{array}{l}\mathrm{K}_{\mathrm{L}}(\mathrm{L} / \\
\mathrm{g})\end{array}$ & $\begin{array}{l}\Delta G \\
(\mathrm{KJ} / \mathrm{mol})\end{array}$ & $\begin{array}{l}\Delta H \\
(\mathrm{KJ} / \mathrm{mol})\end{array}$ & $\begin{array}{l}\Delta S \\
(\mathrm{KJ} / \mathrm{mol} \mathrm{K})\end{array}$ \\
\hline 293 & 0.60 & -22.6 & -126.65 & -0.355 \\
298 & 0.10 & -20.8 & & \\
303 & 0.09 & -19.1 & & \\
308 & 0.05 & -17.3 & & \\
\hline
\end{tabular}

$\mathrm{pH} 8.8$ and $\mathrm{pH} 3.0$, respectively. Final concentration of fluoride achieved when treated at $\mathrm{pH} 3.5$ was $1.46 \mathrm{mg} / \mathrm{L}$ which was below the permissible limit of $1.5 \mathrm{mg} / \mathrm{L}$ as set by WHO (2006). Thus, it can be stated that excess fluoride can be removed from groundwater when it has been treated with CCSFP under optimum condition as analyzed by OFAT. As the defluoridation process was not affected by other co-ions in groundwater, the effectiveness of CCSFP in removal of fluoride from groundwater to supply safe drinking water was established.

\section{Conclusions}

Sal flower, a bio-waste, has been used as precursor for preparation of adsorbent to be used for removal of fluoride. Calcium chloride has been used as activating vis-à-vis impregnating agent to dope calcium onto the surface of adsorbent to facilitate the binding of fluoride. RSM has been used to optimize calcium impregnation condition as well as for optimization of removal of fluoride. The adsorbent prepared at optimum condition is termed as calcium-impregnated carbonized sal flower petal (CCSFP). The wave number of $1253 \mathrm{~cm}^{-1}$ corresponds to strong $\mathrm{C}-\mathrm{F}$ bond indicating the adsorption of fluoride on the Ca-impregnated carbonized adsorbent. EDX studies of CCSFP

Table 7 Adsorption capacities for removal of fluoride using different adsorbents

\begin{tabular}{lll}
\hline Adsorbent & Adsorption capacity (mg/g) & References \\
\hline Citrus fruit peel & $0.36-0.39$ & Chakrapani et al. (2010) \\
Moringa indica-based activated carbon & 0.23 & Karthikeyan and Liango (2007) \\
Powdered biomass (Azadirachta indica + Ficus religiosa + Acacia catechu) & 0.04 & Jamode et al. (2004a, b) \\
Zirconium-impregnated groundnut shell carbon & 2.32 & Alugumuthu and Rajan (2010a) \\
Zirconium-impregnated cashew nut shell carbon & 1.83 & Alugumuthu and Rajan (2010b) \\
Wheat straw raw & 1.93 & Yadav et al. (2013) \\
CCSFP & 5.46 & Present study \\
\hline
\end{tabular}


Table 9 Experimental design and response to optimize fluoride removal

\begin{tabular}{|c|c|c|c|c|}
\hline Run & $\mathrm{IC}(\mathrm{mg} / \mathrm{L})$ & Adsorbent dose $(\mathrm{g} / \mathrm{L})$ & $\mathrm{pH}$ & Removal (\%) \\
\hline 1 & 10.00 & 3.50 & 4.75 & 92 \\
\hline 2 & 10.00 & 3.50 & 4.75 & 92 \\
\hline 3 & 10.00 & 3.50 & 4.75 & 92 \\
\hline 4 & 10.00 & 3.50 & 1.81 & 93 \\
\hline 5 & 15.00 & 5.00 & 6.50 & 82 \\
\hline 6 & 15.00 & 2.00 & 3.00 & 84.2 \\
\hline 7 & 15.00 & 2.00 & 6.50 & 81.2 \\
\hline 8 & 10.00 & 3.50 & 4.75 & 92 \\
\hline 9 & 15.00 & 5.00 & 3.00 & 88.1 \\
\hline 10 & 10.00 & 3.50 & 4.75 & 92 \\
\hline 11 & 10.00 & 3.50 & 7.69 & 83.7 \\
\hline 12 & 5.00 & 5.00 & 3.00 & 96.5 \\
\hline 13 & 5.00 & 2.00 & 6.50 & 93.9 \\
\hline 14 & 1.59 & 3.50 & 4.75 & 95 \\
\hline 15 & 5.00 & 2.00 & 3.00 & 96.2 \\
\hline 16 & 5.00 & 5.00 & 6.50 & 85.5 \\
\hline 17 & 10.00 & 6.02 & 4.75 & 88.5 \\
\hline 18 & 10.00 & 0.98 & 4.75 & 86 \\
\hline 19 & 10.00 & 3.50 & 4.75 & 92 \\
\hline 20 & 18.41 & 3.50 & 4.75 & 83.7 \\
\hline
\end{tabular}

Table 10 Analysis of variance table for fluoride removal study

\begin{tabular}{|c|c|c|c|c|c|}
\hline Source & Sum of squares & $d f$ & Mean square & $F$ value & $\begin{array}{l}p \text { value } \\
\text { Prob }>F\end{array}$ \\
\hline Model & 1.22 & 9 & 0.14 & 35.52 & $<0.0001$ (significant) \\
\hline$A$-IC & 0.64 & 1 & 0.64 & 167.00 & $<0.0001$ \\
\hline$B-\mathrm{Wt}$ & $1.916 \mathrm{E}-004$ & 1 & $1.916 \mathrm{E}-004$ & 0.050 & 0.8269 \\
\hline$C$-pH & 0.30 & 1 & 0.30 & 78.76 & $<0.0001$ \\
\hline$A B$ & 0.058 & 1 & 0.058 & 15.31 & 0.0029 \\
\hline$A C$ & $4.953 \mathrm{E}-003$ & 1 & $4.953 \mathrm{E}-003$ & 1.30 & 0.2804 \\
\hline$B C$ & 0.049 & 1 & 0.049 & 12.82 & 0.0050 \\
\hline$A^{2}$ & 0.032 & 1 & 0.032 & 8.49 & 0.0155 \\
\hline $\mathrm{B}^{2}$ & 0.10 & 1 & 0.10 & 27.54 & 0.0004 \\
\hline$C^{2}$ & 0.062 & 1 & 0.062 & 16.29 & 0.0024 \\
\hline Residual & 0.038 & 10 & $3.804 \mathrm{E}-003$ & & \\
\hline Lack of fit & 0.038 & 5 & $7.608 \mathrm{E}-003$ & & \\
\hline Pure error & 0.000 & 5 & 0.000 & & \\
\hline Cor total & 1.25 & 19 & & & \\
\hline
\end{tabular}



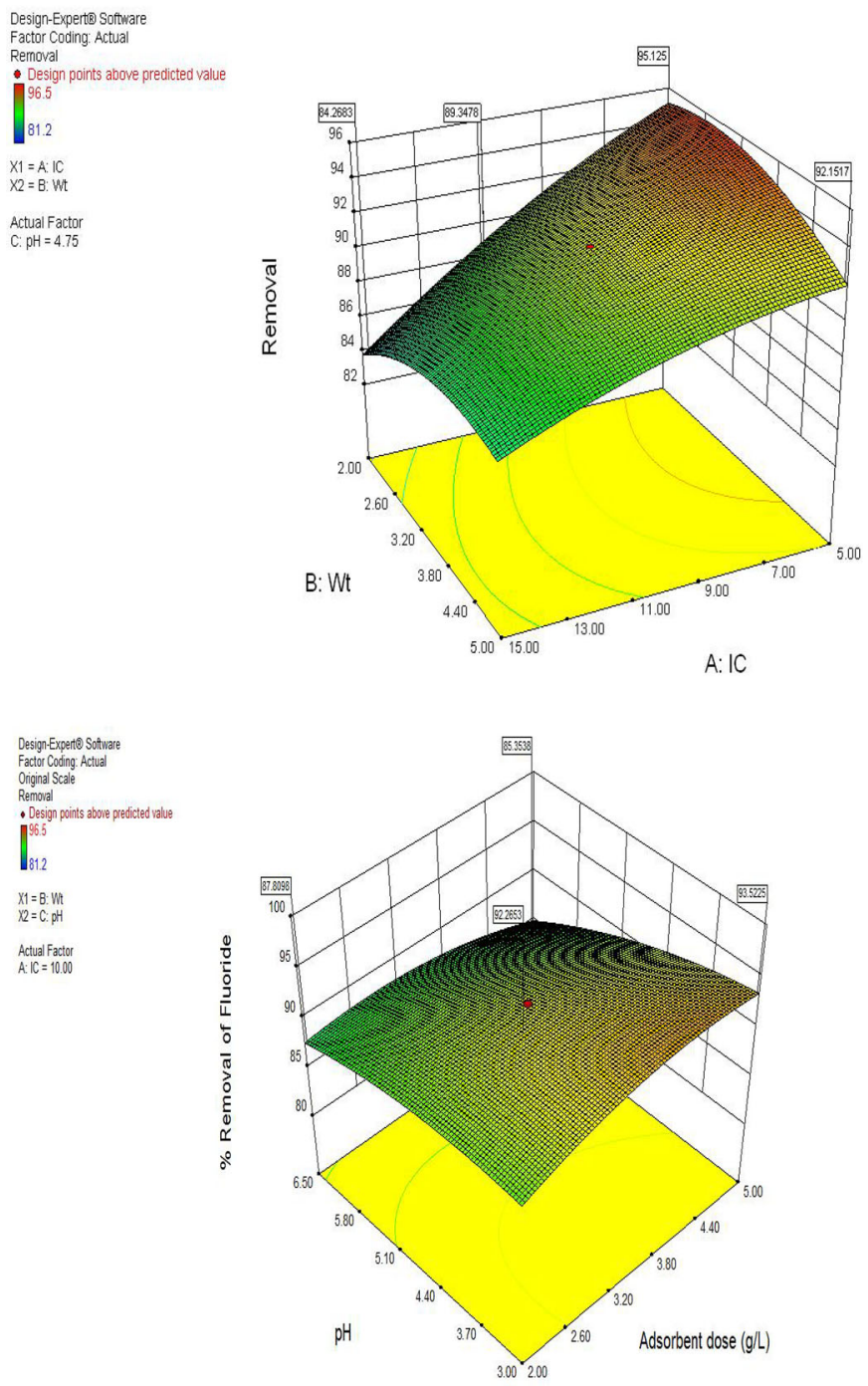

Fig. 9 a Response surface diagram of conjugated effect of adsorbent dose and initial concentration of fluoride for defluoridation study using CCSFP. b Response surface diagram of conjugated effect of $\mathrm{pH}$

and fluoride-loaded CCSFP prove the impregnation of $\mathrm{Ca}$ on SFP and sorption of fluoride onto CCSFP, respectively. Lower $\mathrm{pH}$ has been found to favor the adsorption process, and hence all the kinetic and equilibrium studies have been carried out at $\mathrm{pH}$ 3. Maximum adsorption capacity of CCSFP has been found to be $5.46 \mathrm{mg} / \mathrm{g}$. When groundwater having fluoride concentration of $7.5 \mathrm{mg} / \mathrm{L}$ was treated with CCSFP at an optimum adsorbent dose of $2 \mathrm{~g} /$ $\mathrm{L}, \mathrm{pH} 3.5$, the final concentration of treated water was found to be $1.46 \mathrm{mg} / \mathrm{L}$ which is below the permissible limit. Therefore, it can be concluded that CCSFP has excellent adsorption capability, and hence can be used safely for the removal of fluoride from water.


and adsorbent dose for defluoridation study using CCSFP. $\mathbf{c}$ Response surface diagram of conjugated effect of initial concentration and $\mathrm{pH}$ for defluoridation study using CCSFP

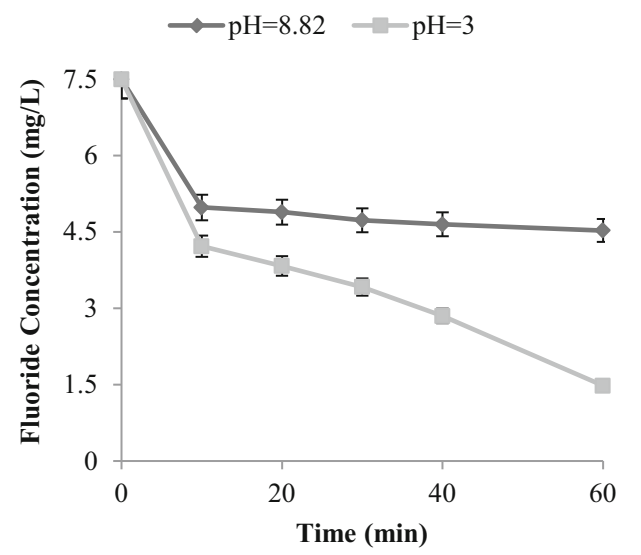

Fig. 10 Removal of fluoride from groundwater collected from Bankura district at different $\mathrm{pH}$ 
Acknowledgements This work is funded by Department of Science and Technology, Govt. of West Bengal. The lab facility is supported by Department of Earth and Environmental studies and Department of Chemical Engineering, National Institute of Technology Durgapur, West Bengal, India.

Open Access This article is distributed under the terms of the Creative Commons Attribution 4.0 International License (http:// creativecommons.org/licenses/by/4.0/), which permits unrestricted use, distribution, and reproduction in any medium, provided you give appropriate credit to the original author(s) and the source, provide a link to the Creative Commons license, and indicate if changes were made.

\section{References}

Agarwal S, Sadeghi N, Tyagi I, Gupta VK, Fakhri A (2016) Adsorption of toxic carbamate pesticide oxamyl from liquid phase by newly synthesized and characterized graphene quantum dots nanomaterials. J Colloid Interface Sci 478:430-438

Alagumuthu G, Rajan M (2010a) Kinetic and equilibrium studies on fluoride removal by zirconium (iv) impregnated groundnut shell carbon. Hem. Ind. 64:295-304

Alagumuthu G, Rajan M (2010b) Equilibrium and kinetics of adsorption of fluoride onto zirconium impregnated cashew nut shell carbon. Chem Eng J 158:451-457

Alkhatib MF, Mamun AA, Akbar I (2015) Application of response surface methodology (RSM) for optimization of color removal from POME by granular activated carbon. Int $\mathrm{J}$ Environ Sci Technol 12:1295-1302

Behbahani M, Alavi Moghaddam MR, Arami M (2011) Technoeconomical evaluation of fluoride removal by electrocoagulation process: optimization through response surface methodology. Desalination 271:209-218

Bhatnagar A, Kumar E, Sillanpää M (2011) Fluoride removal from water by adsorption-a review. Chem Eng J 171:811-840

Bhatti MS, Reddy AS, Kalia RK, Thukral AK (2011) Modeling and optimization of voltage and treatment time for electrocoagulation removal of hexavalent chromium. Desalination 269:157-162

Bhaumik R, Mondal NK (2015) Adsorption of fluoride from aqueous solution by a new low-cost adsorbent: thermally and chemically activated coconut fibre dust. Clean Tech Environ Policy 17:2157-2172

Bhaumik R, Mondal NK (2016) Optimizing adsorption of fluoride from water by modified banana peel dust using response surface modelling approach. Appl Water Sci 6:115-135

Bhaumik R, Mondal NK, Das B, Roy P, Pal KC, Das C, Banerjee A, Datta JK (2012) Eggshell powder as an adsorbent for removal of fluoride from aqueous solution: equilibrium, kinetic and thermodynamic studies. E J Chem 9:1457-1480

Bhaumik R, Mondal NK, Chattoraj S, Datta JK (2013) Application of response surface methodology for optimization of fluoride removal mechanism by newly developed biomaterial. Am J Anal Chem 4:404-419

Biswas G, Dutta M, Dutta S, Adhikari K (2016) A comparative study of removal of fluoride from contaminated water using shale collected from different coalmines in india. Envl Sci Poll Res 23(10):9418-9431

Brindha K, Elango L (2011) Fluoride in groundwater: causes, implications and mitigation measures. Monroy SD. Fluoride Properties, Applications and Environmental Management. Nova Science Publishers, pp 111-136
CEFIC (1986) Test methods for activated carbons, European Council of Chemical Manufacturers' Federations

Chakrabarty S, Sarma HP (2012) Defluoridation of contaminated drinking water using neem charcoal adsorbent: kinetics and equilibrium studies. Int J Chem Tech Res 4:511-516

Chakrapani C, Babu CS, Vani KNK, Rao KS (2010) Adsorption kinetics for the removal of fluoride from aqueous solution by activated carbon adsorbents derived from the peels of selected citrus fruits. E J Chem 7:S419-S427

Chatterjee S, Kumar A, Basu S, Dutta S (2012) Application of response surface methodology for methylene blue dye removal from aqueous solution using low cost adsorbent. Chem Eng J 181-182:289-299

Eugene WR, Rodger BB, Andrew DE, Lenore SC (2012) Standard methods for the examination of water and wastewater. American Public Health Association, American Water Works Association, Water Environment Federation, 22nd edn. Washington DC, USA

Fakhri A (2015) Investigation of mercury (II) adsorption from aqueous solution onto copper oxide nanoparticles: optimization using response surface methodology. Process Saf Environ Protect 93:1-8

Fakhri A (2017) Adsorption characteristics of grapheme oxide as a solid adsorbent for aniline removal from aqueous solutions: Kinetics, thermodynamics and mechanism studies. J Saudi Chem Soc 21:S52-S57

Fakhri A, Adami S (2014) Adsorption and thermodynamic study of Cephalosporins antibiotics from aqueous solution onto $\mathrm{MgO}$ nanoparticles. J Taiwan Inst Chem Eng 45:1001-1006

Fakhri A, Behrouz S (2015a) Comparison studies of adsorption properties of $\mathrm{MgO}$ nanoparticles and $\mathrm{ZnO}-\mathrm{MgO}$ nanocomposites for linezolid antibiotic removal from aqueous solution using response surface methodology. Process Saf Environ Protect 94:37-43

Fakhri A, Behrouz S (2015b) Improved uptake of steroid hormone from aqueous solution using $\gamma-\mathrm{Fe}_{2} \mathrm{O}_{3} / \mathrm{NiO}$ nanocomposites. J Indus Eng Chem 26:61-66

Ganvir V, Das K (2011) Removal of fluoride from drinking water using aluminum hydroxide coated rice husk ash. J Haz Mat 185:1287-1294

Garg UK, Kaur MP, Garg VK, Sud D (2008) Removal of Nickel(II) from aqueous solution by adsorption on agricultural waste biomass using a response surface methodological approach. Bioresour Technol 99:1325-1331

Ghosh SB, Bhaumik R, Mondal NK (2016) Optimization study of adsorption parameters for removal of fluoride using aluminiumimpregnated potato plant ash by response surface methodology. Clean Techn Environ Policy 18:1069-1083

Gupta VK, Agarwal S, Asifb M, Fakhri A, Sadeghi N (2017) Application of response surface methodology to optimize the adsorption performance of a magnetic graphene oxide nanocomposite adsorbent for removal of methadone from the environment. J Colloid Interface Sci 497:193-200

Habuda-Stanić M, Ravančić ME, Flanagan A (2014) A review on adsorption of fluoride from aqueous solution. Materials 7:6317-6366

Hernández-Montoya V, Ramírez-Montoya LA, Bonilla-Petriciolet A, Montes-Morán MA (2012) Optimizing the removal of fluoride from water using new carbons obtained by modification of nut shell with a calcium solution from egg shell. Biochem Eng $\mathbf{J}$ 62:1-7

Jamode AV, Sapkal VS, Jamode VS (2004a) Defluoridation of water using inexpensive adsorbents. J Indian Inst Sci 84:163-171

Jamode B, Chandak S, Rao M (2004b) Evaluation of performance and kinetic parameters for defluoridating using Azadirachta indica (neem) leaves as low cost adsorbents. Poll Res 23:239-250

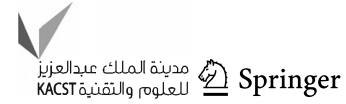


Karthikeyan M, Elango KP (2008) Removal of fluoride from aqueous solution using graphite: a kinetic and thermodynamic study. Indian J Chem Technol 15:525-532

Karthikeyan G, Llango SS (2007) Fluoride sorption using Moringa indica based activated carbon. Iran J Environ Health Sci Eng 4:21-28

Khuri AI (1996) Multiresponse surface methodology. In: Ghosh S, Rao CR (eds) Handbook of statistics. Elsevier Science B.V, Amsterdam, pp 377-406

Kumar BGP, Shivakamy K, Miranda LM, Velan M (2006) Preparation of steam activated carbon from rubberwood sawdust (Hevea brasiliensis) and its adsorption kinetics. J Hazard Mater 136:922-929

Kumar S, Gupta A, Yadav JP (2008) Removal of fluoride by thermally activated carbon prepared from neem (Azadirachta indica) and kikar (Acacia arabica) leaves. J. Environ Biol 29:227-232

Kushwaha D, Dutta S (2017) Experiment, modeling and optimization of liquid phase adsorption of $\mathrm{Cu}(\mathrm{II})$ using dried and carbonized biomass of Lyngbya majuscula. Appl Water Sci. 7:935-949

Meenakshi, Maheshwari RC (2006) Fluoride in drinking water and its removal. J Hazard Mater 137:456-463

Mohapatra M, Anand S, Mishra BK, Giles DE, Singh P (2009) Review of fluoride removal from drinking water. J Environ Manag 91:67-77

Mondal NK, Das B, Bhaumik R, Bour T, Roy P (2012) Calcareous soil as a promising adsorbent to remove fluoride from aquous solution: equilibrium, kinetic and thermodynamic study. J Mod Chem Technol 3(3):1-21

Mondal D, Gupta S, Mahato A (2013) Fluoride dynamics in the weathered mantle and the saprolitic zone of the Purulia district, West Bengal. Adv Appl Sci Res 4:187-196

Mondal NK, Bhaumik R, Datta JK (2015) Removal of fluoride by aluminium impregnated coconut fiber from synthetic fluoride solution and natural water. Alexan Eng J. 54:1273-1284

Mouelhi M, Marzouk I, Hamrouni B (2015) Optimization studies for water defluoridation by adsorption: application of a design of experiments. Desalination Water Treat. doi:10.1080/19443994. 2015.1032363

Myers RH, Montgomery DC, Anderson-Cook CM (2005) Response surface methodology: process and product optimization using designed experiments, 3rd edn. Wiley, New Jersey, pp 49-327

Ozer A, Gurbuz G, Calimli A, Korbahti BK (2009) Biosorption of copper (II) ions on Enteromorpha prolifera: application of response surface methodology (RSM). Chem Eng J 146:377-387

Razbe N, Kumar R, Pratima Kumar R (2013) Various options for removal of fluoride from drinking water. Int Organ Sci Res J Appl Phys 3:40-47

Rehman MA, Yusoffa I, Alias Y (2015) Fluoride adsorption by doped and un-doped magnetic ferrites cuce $_{\mathrm{x}} \mathrm{fe}_{2-\mathrm{x}} \mathrm{O}_{4}$ : preparation, characterization, optimization and modelling for effectual remediation technologies. J Haz Mat 299:316-324

Richards LA, Richards BS, Rossiter HMA, Schafer AI (2009) Impact of speciation on fluoride, arsenic and magnesium retention by nanofiltration/reverse osmosis in remote Australian communities. Desalination 248:177-183

Sadhu K, Mukherjee A, Shukla SK, Adhikari K, Dutta S (2013) Adsorptive removal of phenol from coke-oven wastewater using Gondwana shale, India: experiment, modelling and optimization. Desalin Water Treat 52:6492-6504

Sen S, Dutta S, Guhathakurata S, Chakrabarty J, Nandi S, Dutta A (2017) Removal of Cr(VI) using a cyanobacterial consortium and assessment of biofuel production. Int Biodet Biodeg. 119:211-224

Silverstein RM, Bassler GC, Morrill TC (1981) Spectrometric identification of organic compounds, 4th edn. Wiley, New York

Tentli-Sequeira A, Solache-Ríos M, Martínez-Miranda V, LinaresHernández I (2014) Comparison of aluminium modified natural materials in the removal of fluoride ions. J Colloid Interface Sc 418:254-260

Viswanathan N, SairamSundaram C, Meenakshi S (2009) Development of multifunctional chitosan beads for fluoride removal. J Hazard Mater 167:325-331

WBPHED (2006) http://www.wbphed.gov.in/main/images/pdf/ Fluoride_Reports/FLDistrictwise_A4.pdf. Accessed 10 May 2017

Weinstein LH, Davison A (2004) Uptake, transport and accumulation of inorganic fluorides by plants and animals; fluorides in the environment; effects on plants and animals. CABI Publishing, London, pp 21-55

WHO (2006) Guidelines for drinking water quality. World Health Organization, Geneva

Yadav AK, Abbassi R, Gupta A, Dadashzadeh M (2013) Removal of fluoride from aqueous solution and groundwater by wheat straw, sawdust and activated bagasse carbon of sugarcane. Ecol Eng $52: 211-218$

Zhang Z, Tan Y, Zhong M (2011) Defluorination of wastewater by calcium chloride modified natural zeolite. Desalination 276:246-252

Zhang Z, Feng X, Yue XX, An FQ, Gao JF, Zhou WX, Hu TP, Wei CC (2015) Effective adsorption of phenols using nitrogencontaining porous activated carbon prepared from sunflower plates. Korean J Chem Eng 32:1564-1569

\section{Publisher's Note}

Springer Nature remains neutral with regard to jurisdictional claims in published maps and institutional affiliations. 